\title{
Phänotypische Vielfalt der Südtiroler Getreidelandsorten
}

\author{
Phenotypic diversity of the cereal landraces of South Tyrol \\ La diversità fenotipica delle varietà locali di cereali della Provincia di Bolzano
}

\author{
Giovanni Peratoner ${ }^{1}$, Caterina Sartori ${ }^{1}$, Franziska Schwienbacher ${ }^{2}$, Andreas Kasal ${ }^{3}$ \\ ${ }^{1}$ Versuchszentrum Laimburg, Pfatten, Italien \\ 2 Versuchszentrum Laimburg; aktuell: Winterschule Ulten, Ulten, Italien \\ ${ }^{3}$ Versuchszentrum Laimburg; aktuell: Amt für Bergwirtschaft, Bozen, Italien
}

\section{ABSTRACT}

The programme of the Laimburg Research Centre aiming at collecting the landraces still occurring in South Tyrol has led to the constitution of a relatively rich collection of the most important cereal species of the Alps. Detecting duplicates and quantifying the similarity of different accessions is an important issue, in order to evaluate the diversity of the gene bank collection. In the course of the Interreg III A GENE-SAVE project, 89 landraces of wheat, rye, barley, and oat, collected between 1993 and 2008 and stored in the gene bank of the Region of the Tyrol, were phenotypically described. The evaluation of the phenotypic diversity by methods of descriptive statistics revealed that descriptions made in different years and/or at different sites are not comparable. For this reason, the phenotypic characterisation of the whole collection of a species should be carried out at one site in a single year. If the results of single description field trials are considered, a relatively high diversity within each crop collection with just few cases of possible duplicates was found. In only one case was it possible to explain the duplicate occurrence on the basis of the passport data. Thanks to their diversity, the landraces represent an important gene reservoir for the future. The phenotypic characterisation can complement the information gained through genetic analyses or represent a technology-poor alternative to it.

\section{KEYWORDS}

South Tyrol, landraces, phenotypic diversity, rye, wheat, barley, oat

\section{CITE ARTICLE AS}

Peratoner Giovanni, Sartori Caterina, Schwienbacher Franziska et.al. (2020). Phenotypic diversity of the cereal landraces of South Tyrol. Laimburg Journal 02/2020 DOI: $10.23796 /$ LJ/2020.001

\section{CORRESPONDING AUTHOR}

Giovanni Peratoner Laimburg 6, Pfatten, I-39040 Auer (BZ), Italien giovanni.peratoner@laimburg.it +390471969661 


\section{EINLEITUNG}

Die Landsorten sind traditionelle Sorten, die im Laufe der Zeit durch Umweltselektion und durch bewusste oder unbewusste Auslese seitens der Bauern an einem bestimmten Standort entstanden sind [1] [2]. Die Landsorten werden oft auch als Hofsorten, Lokalsorten oder alte Landsorten bezeichnet. Jeder dieser Begriffe bezieht sich auf eine typische Eigenschaft der Landsorten. Hofsorte unterstreicht die enge Verbindung zwischen einer Landsorte und dem Hof, an dem die Landsorte entstanden ist. Dadurch wird auch die Rolle des Bauern bei der Entstehung und der Weitervermehrung der Landsorte hervorgehoben. Die Bezeichnung als Lokalsorte betont hauptsächlich die regionale Herkunft der Landsorten bzw. ihre Bindung an einen bestimmten Standort. Alte Landsorte wirft ein zusätzliches Schlaglicht auf den traditionellen Charakter dieser Kulturpflanzen. Bei der vorliegenden Arbeit wird der Begriff Landsorte (Engl. „landrace“, It. „varietà locale“), der sich in der Fachliteratur durchgesetzt hat, konsequent verwendet.

Bevor die Pflanzenzüchtung von Forschungsanstalten und spezialisierten Unternehmen übernommen wurde, war sie Bestandteil der Arbeit eines jeden Landwirtes. Der Bauer war Landsortenzüchter und -erhalter zugleich. Das ermöglichte die Entstehung zahlreicher Landsorten, die den lokalen Bedingungen (Klima, Boden usw.) angepasst waren. Die Vielfalt der Landsorten wurde unter anderem vom Saatgutersatz und -austausch mit anderen Bauern sowie von der Vermischung mit hofeigenem Vermehrungsmaterial beeinflusst [3] [4] [5] [6]. Als um 1850 die moderne Züchtung mit der Selektion von Linien aus Landsorten begann [7] [8] [9] [10], trennten sich die Bereiche Anbau und Züchtung. Die Landsorten sahen sich schnell der Konkurrenz von Zuchtsorten ausgesetzt, die unter günstigeren Bedingungen selektiert worden waren [5] und einheitliche Sorten mit hohem Ertragspotential ersetzten allmählich die Landsorten [11]. Während des "Getreidekampfes" wurde zum Beispiel in Südtirol unter der faschistischen Diktatur die Einführung von ertragreicheren Weizensorten angestrebt [12].

Die Gefährdung der Landsorten wurde bereits am Ende des 19. Jahrhunderts erkannt. Die ersten Empfehlungen zur Erhaltung der Vielfalt der Kulturpflanzen wurden im Jahr 1927 auf Europäischer Ebene erarbeitet, erwiesen sich aber als ungeeignet, um die
Vielfalterosion anzuhalten [6]. Eine rege Sammeltätigkeit fand zwischen dem 1. und dem 2. Weltkrieg statt [13]. Die ersten Maßnahmen zur ex-situ-Erhaltung der Landsorten in Genbanken wurden in der Nachkriegszeit und auf intensiver Art und Weise seit den 60er Jahren unternommen [7].

Schon seit Anfang der 90er Jahre hat das Versuchszentrum Laimburg eine Sammelaktion der noch lokal erhaltenen Landsorten vorgenommen. Im Laufe des Interreg III A Projektes GENE-SAVE ist es dann zusätzlich möglich gewesen, eine intensive fünfjährige Sammlungskampagne durchzuführen. Dadurch entstanden relativ umfangreiche Sortimente der wichtigsten Getreidearten (Anhang 3). Dabei stellen sich die zentralen Fragen, ob die gesammelten Herkünfte sich tatsächlich voneinander unterscheiden und wie die Ähnlichkeit zwischen den Herkünften quantifiziert werden kann. Denn es ist nicht auszuschließen, dass dieselbe Landsorte an mehreren Standorten wiederholt gesammelt wurde. Schon vor Beginn der modernen Züchtungsprogramme konnte das Saatgut erfolgreicher Landsorten auf dem Markt erworben werden [14]; damit war die Möglichkeit des Anbaus der Landsorten an mehreren Standorten gegeben. Auch der frühere Saatgutersatz und -austausch mit anderen Bauern und die Vermischung mit dem hofeigenen Vermehrungsmaterial haben in dieser Hinsicht eine wichtige Rolle gespielt. Besonders im Fall von Fremdbefruchtern könnte auch die häufig wiederholte Kreuzung zwischen Landsorten in Nachbarfeldern zur Vermischung und genetischen Nivellierung unterschiedlicher Herkünfte führen.

Die phänotypische Beschreibung besteht aus der Bonitur bzw. Messung verschiedener Pflanzenmerkmale, um die Erkennung der jeweiligen Sorte zu ermöglichen und das Vorhandensein von Duplikaten zu entdecken. Da die Landsorten sich meistens aus mehreren phänotypischen Linien zusammensetzen, die im Pflanzenbestand mit unterschiedlichen Anteilen vertreten sind, bereitet die Beschreibung besondere Schwierigkeiten. Dazu kommt die Subjektivität der Bonitur rein qualitativer Merkmale, wenn ihre Ausprägung Zwischenpunkte zwischen den festgelegten Merkmalsstufen aufweist. Unter diesen Umständen ist die Frage, ob sich zwei Herkünfte tatsächlich voneinander unterscheiden, schwer zu beantworten.

Ziel der vorliegenden Arbeit war es, eine Methodik zur phänotypischen Beschreibung, zur Identifizierung von Duplikaten sowie zur Evaluierung der intraspezifischen Vielfalt der Getreidesortimente zu entwickeln.

Ziel dieser Studie ist die Vorstellung der Ergebnisse der ersten breit durchgeführten phänotypischen Charakterisierung der Landsorten von Weizen (Triticum aestivum), Roggen (Secale cereale), Gerste (Hordeum vulgare) und Hafer (Avena sativa) sowie eine Quantifizierung der Diversität der verschiedenen Sortimente.

\section{MATERIAL UND METHODEN}

89 Landsorten der in Südtirol am häufigsten angebauten Getreidearten wurden untersucht: 39 Winterroggen, 19 Hafer, 14 Sommergerste, 9 Sommerweizen, 5 Winterweizen, 3 Sommerroggen. 83 davon waren Südtiroler Herkünfte, 6 Akzessionen (4 Sommergerste und 2 Sommerweizen) stammten aus dem Kanton Graubünden (Schweiz) und wurden als Vergleichssorten angebaut. Das Untersuchungsmaterial bestand aus Landsorten, die seit Anfang der 90er Jahre auf Südtiroler Bergbauernhöfen gesammelt wurden und in der Genbank des Landes Tirol in Innsbruck durch Lagerung unter standardisierten Bedingungen sowie regelmäßigem Regenerierungsanbau aktuell gesichert sind. Die Schweizer Landsorten sind Teil der Getreidesammlung der Genbank der ACW Changins ( $\mathrm{CH})$. Die Landsorten aus der Genbank des Landes Tirol unterlagen während der Regenerationsphasen keiner Trennung in phänotypische Linien, sodass sich die Ergebnisse der vorliegenden Untersuchungen auf Landsorten als potentielle Liniengemische beziehen. Bei den Schweizer Akzessionen handelt es sich um Linien, die aus Landsorten bereits selektiert wurden.

Die aus Südtirol stammenden Landsorten sind in der vorliegenden Arbeit durch den sogenannten Laimburg Code gekennzeichnet. Es handelt sich um eine alphanumerische Codierung, die sich aus dem Buchstaben „L“ (für Laimburg), den Initialen des lateinischen Namens der Art („TA“ für Weizen, „SC“ für Roggen, „HV“ für Gerste und „AS“ für Hafer), dem Zusatzteil „,ae“ wenn zutreffend (nur für die Sommerformen) und einer dreistelligen Ziffer zusammensetzt. Die Schweizer Landsorten sind bei Weizen mit einer vierstelligen Ziffer codiert (Landsorten 4425 und 4430). Bei Gerste wurden die Akzessionen mit der Codierung HV48, HV57, HV553 und HV714 untersucht. 


\section{PRÜFUNGSSTANDORTE}

Der Anbau und die Beschreibung der Landsorten erfolgte an insgesamt 3 Standorten zwischen 735 und $850 \mathrm{~m}$ ü. NN (Eyrs im Vinschgau, Fragsburg im Burggrafenamt und Dietenheim im Pustertal), die sich untereinander bezüglich klimatischer und edaphischer Eigenschaften relativ stark unterscheiden (Tab. 1). Der Standort Eyrs zeichnet sich bei günstiger Nährstoffverfügbarkeit durch eine alkalische Bodenreaktion und besonders niedrige Niederschlagsmengen aus. Sie wurden an diesem Standort durch künstliche Bewässerung ausgeglichen. Am Standort Fragsburg ereigneten sich die höchsten Temperaturen und die auf Grund der fehlenden Bewässerung niedrigste Wasserverfügbarkeit. Dieser Standort wies eine leicht saure Bodenreaktion und mittelmäßige Nährstoffversorgung auf. Der Standort in Dietenheim hatte ähnliche Bodeneigenschaften wie der Standort Fragsburg bei einem günstigeren Witterungsverlauf.

\section{AUFBAU DER VERGLEICHSANBAU- VERSUCHE}

Der Anbau der Landsorten erfolgte in Kleinparzellen, deren Fläche zwischen 5,2 und $20 \mathrm{~m}^{2}$ schwankte (Tab. 2). Nach der Breitsaat wurde das Saatgut mit einem Rechen leicht in den Boden eingearbeitet. Die Drillsaat erfolgte zum Teil mit der Parzellensämaschine trm 2200 Plotmatic E.R.S. (Wintersteiger, Ried, A), zum Teil mit der Handsämaschine Sembdner H 70 (Sembdner, Germering, D). In allen Fällen wurde eine Ablagetiefe von $2 \mathrm{~cm}$ angestrebt.

In jedem Vergleichsanbaufeld wurden eine oder mehrere Referenzsorten eingeschlossen. Die Landsorten wurden ohne Wiederholungen angebaut, während mehrere Parzellen der Referenzsorten in mehr oder weniger regelmäßigen Abständen im Versuch vorhanden waren. Dadurch war es möglich, Informationen zur räumlichen Variabilität des Feldes zu bekommen.

Die meisten Referenzsorten waren moderne Zuchtsorten. Einige waren hingegen ausgewählte Schweizer Landsorten, die sich im Anbau in der Schweiz bereits behauptet hatten. Die Winterroggensorte Cadi ist zum Beispiel eine Kreuzung der alten Zuchtsorte Petkuser mit einer Landsorte vom Bündner Oberland (Fellers/Falera), welche in den 50er Jahren für das Berggebiet gezüchtet wurde [15].

\section{PHÄNOTYPISCHE BESCHREIBUNG}

Je nach Getreideart wurden zwischen 30 und 36 Deskriptoren (phänotypische Merkmale) eingesetzt, um die Landsorten zu beschreiben (Tab. 3).

Die Deskriptoren wurden nach Hidalgo (2003) [16] in drei Kategorien klassifiziert:

- qualitative nominalskalierte Boniturmerkmale (z.B. Spelzenfarbe), im folgenden Text als qualitativ bezeichnet;

- qualitative ordinalskalierte Boniturmerkmale (z.B. Halmbereifung von fehlend bis sehr stark), im folgenden Text als halbquantitativ bezeichnet, da die Beurteilung des Merkmals aufgrund einer quantitativen Skala im Hintergrund erfolgt;

- quantitativ gemessene Merkmale (z.B. Ertrag), im folgenden Text als quantitativ bezeichnet. Diese Kategorie umfasst sowohl diskrete als auch kontinuierliche Merkmale.

Eine detaillierte Beschreibung der verwendeten Deskriptoren ist im Anhang $4 \mathrm{zu}$ finden. Jedes Merkmal wurde bonitiert bzw. gemessen, wenn ein festgelegtes Entwicklungsstadium von $50 \%$ des Pflanzenbestandes erreicht wurde. Die Entwicklungsstadien wurden nach der BBCH-Skala der entsprechenden Kulturpflanze definiert [17]. Die Versuchsflächen wurden in der Vegetationsperiode alle 2-4 Tage besucht. Einige Deskriptoren bestehen aus einem Datum, in dem ein bestimmtes Entwicklungsstadium erreicht wird. Wenn das Entwicklungsstadium an einem Tag zwischen zwei aufeinander folgenden Besuchen erreicht wurde, wurde als Datum dasjenige angegeben, das in der Mitte zwischen den Beobachtungsterminen lag. Die Beschreibung erfolgte meistens durch 2 Personen, um die Subjektivität der Bonitur in Grenzen zu halten. Die quantitativen Merkmale zur Beschreibung der Pflanzenmorphologie wurden an 5-7 zufällig ausgewählten Pflanzen gemessen. Beim gleichzeitigen Auftreten mehrerer Stufen desselben quantitativen oder halbquantitativen Merkmales im Pflanzenbestand wurden mehrere Boniturnoten vergeben. Dabei wurde zusätzlich zwischen quantitativ dominanten Merkmalsstufen und sporadisch vertretenen Merkmalsstufen unterschieden.

In den meisten Fällen erfolgte die Ernte maschinell mit dem Parzellenmähdrescher Classic (Wintersteiger, Ried, A) (Tab. 2). Bei der Handernte wurden die Parzellen mit der Sichel geschnitten und das Erntegut zu Garben gebunden und getrocknet. $\mathrm{Zu}$ einem späteren Zeitpunkt wurden dann die Garben mit dem Allesdrescher K35 (Baumann Saatzuchtbedarf, Waldenburg, D) gedroschen. In den maschinell geernteten Feldern wurden die früh reifenden Landsorten mit der Sichel geerntet. Die daraus resultierenden Garben wurden beim Mähdrusch der restlichen Landsorten mit dem Parzellenmähdrescher gedroschen. Das gedroschene Getreide wurde unmittelbar nach der Ernte in Stoffsäcken bei $30^{\circ} \mathrm{C} 4$ Tage lang getrocknet und anschließend mit dem Allesdrescher gereinigt.

Bis zur Durchführung der Saatgutbeschreibung und der Qualitätsanalysen wurde das gereinigte Getreide in Papiersäcken bei Raumtemperatur gelagert. Die Messungen und die Bonitur der phänotypischen Samenmerkmale wurden am getrockneten und gereinigten Erntegut durchgeführt. Das Tausendkorngewicht (TKG) wurde mit einer Änderung der Anzahl der Wiederholungen in Anlehnung an die Methodik von ISTA (1996) [18] durchgeführt. Zuerst wurden drei Proben von je 100 Samen gewogen und der entsprechende Variationskoeffizient berechnet. Im Fall einer Überschreitung des Grenzwertes (4\%) nach ISTA (1996) [18], wurden zusätzliche Messungen durchgeführt, bis der Grenzwert unterschritten wurde.

\section{DATENAUFBEREITUNG UND STA- TISTIK}

Um die Vielfalt der beschriebenen Sortimente beurteilen zu können, wurden die phänotypischen Daten mit Methoden der beschreibenden Statistik analysiert. Bei der Vorbereitung der Daten für die Analyse wurden jene Merkmale ausgeschlossen, welche Lücken in der Datenerhebung aufwiesen (Tab. 4). Für jede Stufe der qualitativen und halbqualitativen Merkmale wurde eine kategoriale Variable erzeugt, und für jede beschriebene Landsorte wurde der Wert 0 für das Fehlen, der Wert 1 für das sporadische Vorkommen oder der Wert 2 für das dominante Vorkommen dieser Merkmalsstufe vergeben. Somit wurde das Gewicht der sporadisch vertretenen Merkmalsstufen willkürlich auf die Hälfte des Wertes der dominanten Merkmalsstufen festgelegt. Dadurch wurde ein halbquantitatives Kriterium für die Evaluierung der Diversität eingeführt. Halbquantitative Daten wurden als qualitative Daten behandelt, weil in den meisten Fällen mehr als ein Phänotyp in der Landsorte vertreten war und kein Mittelwert gebildet werden konnte, ohne die Information des Vorhandenseins mehrerer 
Phänotypen zu verlieren und die qualitative Information zu verfälschen. Die Werte jeder Variablen wurden durch Abzug des Mittelwerts und Dividierung durch die Standardabweichung standardisiert [19]. Daraus resultiert eine Verteilung mit Mittelwert gleich null und Varianz gleich eins.

Um homogene Fallgruppen von Landsorten zu identifizieren und mögliche Duplikate in der Sammlung aufzudecken, wurde eine hierarchische Clusteranalyse durchgeführt. Dabei wurde die Distanzmatrix der beschriebenen Sorten jeder Kulturpflanze mittels Euklidischer Distanz berechnet und der nächstgelegene Nachbar (single linkage) als Methode der Clusterbildung verwendet [20]. Die multidimensionale Darstellung der Ähnlichkeit zwischen den beschriebenen Akzessionen erfolgte durch multidimensionale Skalierung (MDS), die aus derselben Distanzmatrix mit der Prozedur PROXSCAL Version 1.0 (DTSS, Leiden University) von SPSS 12 (SPSS Inc., Chicago, U.S.A.) durchgeführt wurde.

Für jeden Datensatz wurden die Zentroidkoordinaten als Mittelwerte aller Werte der jeweiligen Variablen berechnet. Für diese Analyse wurden die Beschreibungen der Referenzsorten und der schweizerischen Landsorten nicht berücksichtigt. Nach erfolgter Standardisierung wurde die Euklidische Distanz jeder Landsortenbeschreibung zum Zentroid berechnet. Als Index der Sortimentvielfalt der einzelnen Kulturpflanzen wurde der Mittelwert der Euklidischen Distanzen zum Zentroid herangezogen.

\section{ERGEBNISSE}

\section{WEIZEN (TRITICUM AESTIVUM)}

Die multidimensionale Skalierung aller verfügbaren phänotypischen Beschreibungen (2 Standorte, 3 Beobachtungsjahre) wies eine räumliche Gruppierung der drei unterschiedlichen Kombinationen von Jahr und Standort auf (Abb. 1). Mit wenigen Ausnahmen war dabei eine Trennung zwischen Sommer- und Winterformen entlang der ersten Dimension deutlich zu erkennen.

Die Bewertung der Diversität des Weizensortimentes erfolgte anhand der Daten des Jahres 2004, in dem zusätzliche Landsorten aus der Schweiz beschrieben wurden. Während beim Winterweizensortiment die Beschreibungen der zweimal angebauten Referenz Casut untereinander die niedrigste Distanz $(8,1)$ aufwiesen, lag eine Sortengruppe (LTAae025, LTAae037 und LTAae029) des Sommerweizensortimentes auf einem Diversitätsniveau, das niedriger als dasjenige der Referenzsorte Fasan $(8,4)$ war (Abb. 2). Besonders die Euklidische Distanz zwischen den Sommerweizensorten LTAae 025 und LTAae037 war auffallend kleiner als diejenige der Referenzsorte. Die ersten zwei Dimensionen der multidimensionalen Skalierung der phänotypischen Daten ermöglichten eine klare Trennung zwischen Winter- und Sommersorten (Abb. 3). Der Mittelwert der Euklidischen Distanzen der beschriebenen Sorten zum Zentroid betrug 7,9 .

\section{ROGGEN (SECALE CEREALE)}

Auch beim Roggen ergab die multidimensionale Skalierung aller erfolgten Beschreibungen (drei Standorte an drei unterschiedlichen Jahren) eine deutliche Trennung sowohl anhand der Kombinationen von Standort und Jahr als auch anhand der Saisonalität (Abb. 4).

Die Bewertung der Diversität des Winterroggensortimentes erfolgte auf der Basis zweier getrennter Datensätze (Vergleichsanbau Fragsburg im Jahr 2005 und Vergleichsanbau Dietenheim im Jahr 2006), welche keine Referenz- und Landsorten gemeinsam hatten. Am Standort Fragsburg wiesen die Beschreibungen der dreimal angebauten Referenz Cadi ein Diversitätsniveau (7,2 im Durchschnitt) auf, das höher als dasjenige der Landsortengruppe LSC057, LSCO45 und LSCO41 war und demjenigen des Landsortenpaares LSCO6O und LSC056 ähnlich war (Abb. 5).

Besonders niedrig $(3,4)$ war die Euklidische Distanz zwischen den Landsorten LSCO57 und LSC045. Die multidimensionale Skalierung zeigte eine relativ breite Streuung der Landsortenbeschreibungen im dreidimensionalen Raum (Abb. 6) mit einem hohen Mittelwert $(8,7)$ der Euklidischen Distanzen der beschriebenen Sorten zum Zentroid.

Am Standort Dietenheim war die Distanz zwischen den zwei Referenzbeschreibungen am niedrigsten $(3,6)$, während alle anderen möglichen Landsortenpaare ab einer Euklidischen Distanz von 8,7 clusterten. Das Dendrogramm (Abb. 7) und die multidimensionale Skalierung (Abb. 8) zeigten eine deutliche Trennung von Referenz und Landsorten und eine relativ gleichmäßige Verteilung der Landsorten im dreidimensionalen Raum. Der Mittelwert der Euklidischen Distanzen der beschriebenen Landsorten zum Zentroid war niedriger als derjenige des Versuchs aus dem Jahr 2005 und betrug 7,7 .

\section{GERSTE (HORDEUM VULGARE)}

Zwei Sortenpaare des Sommergerstensortimentes (LHVae011 und LHVae016 sowie LHVae013 und LHVae024) clusterten auf einem niedrigeren Diversitätsniveau als die viermal wiederholten Beschreibungen der Referenzsorte Alpina (Abb. 9) und waren als solche im von der multidimensionalen Skalierung dargestellten dreidimensionalen Raum leicht erkennbar (Abb. 10). Der Mittelwert der Euklidischen Distanzen der beschriebenen Landsorten zum Zentroid war der niedrigste aller untersuchten Kulturpflanzen und betrug 7,0 .

\section{HAFER (AVENA SATIVA)}

Die vier Beschreibungen der Referenz Expander wiesen das niedrigste Diversitätsniveau auf (5,5 im Durchschnitt) und befanden sich in einer eigenen Gruppe im Dendrogramm (Abb. 11). Alle Landsorten clusterten bei höheren Diversitätsniveaus mit einigen Fällen (LASO03, LASO17), die sich deutlich von den anderen differenzierten und bei der multidimensionalen Skalierung eine Randstellung innerhalb des dreidimensionalen Raums einnahmen (Abb. 12). Somit erreichte das Hafersortiment den höchsten Mittelwert der Euklidischen Distanzen der beschriebenen Landsorten zum Zentroid $(8,2)$.

\section{DISKUSSION}

\section{ANGEWANDTE METHODIK ZUR BE- URTEILUNG DER VIELFALT}

Die verwendete Methodik kombinierte qualitative, halbquantitative und quantitative Merkmale für die Beurteilung der Unähnlichkeit mehrerer Landsorten anhand beschreibender statistischer Verfahren. Die Berechnung der Diversität sah im Gegensatz zu Cole-Rodgers et al. (1997) [21] keine Reduzierung des Gewichtes der qualitativen Merkmale vor, sodass Merkmale mit zahlreichen Stufen (z.B. Rispenform im Hafer) ein höheres Gewicht als Merkmale mit wenigen Stufen besitzen. Das basiert auf der Überlegung, dass die quantitativen Merkmale wenig geeignet sind, die Diversität von Landsorten zu evaluieren, die mehrere phänotypische Linien besitzen. Quantitative Merkmale werden nämlich von einem einzigen Wert beschrieben, der hauptsächlich Informationen zur dominanten Linie liefert. Gerade 
qualitative, stufenreiche Merkmale, die eher die Ausnahme bildeten, wurden als wichtige Chance betrachtet, die Linienvielfalt korrekt darzustellen. Somit minimiert die Methode das Risiko, unterschiedliche Sorten als Duplikate zu identifizieren, kann aber die Diversität überschätzen. Die Trennung der Landsorten in homogene phänotypische Linien und ihre Sicherung parallel zu den Landsorten als Liniengemische wird als eine wichtige Aufgabe betrachtet, um Linienverluste im Laufe der Saatgutregeneration zu vermeiden und eine genaue Charakterisierung aller Linien zu ermöglichen [22]. Diese Trennung ist für die Südtiroler Getreidesortimente zum Teil bereits erfolgt. Die einzelnen Linien können leichter beschrieben und untereinander verglichen werden. Dabei wäre sowohl die Gewichtsvereinheitlichung nach Cole-Rodgers et al. (1997) [21] als auch die Behandlung halbquantitativer Merkmale als quantitative möglich, was die Wahrscheinlichkeit einer Überschätzung der Diversität reduzieren würde.

Die Cluster Analysis und die multidimensionale Skalierung zeigten eine deutliche Gruppierung nach der Saisonalität. Das war zu erwarten, da die Saisonalität selbst als qualitatives Merkmal und das Erreichen bestimmter phänologischer Entwicklungsstadien (als Tage ab der Aussaat ausgedrückt) sich unter den verwendeten Deskriptoren befanden. Dadurch wurde eine gewisse Redundanz der Information bezüglich der Saisonalität verursacht. Diese Trennung trat allerdings auch bei den Ergebnissen des Versuchs mit Weizen in Eyrs 2004 klar hervor, bei dem das Datum Mitte Ährenschieben für die Berechnung der Euklidischen Distanz nicht verwendet wurde. Das deutet darauf hin, dass auch andere Merkmale eine Rolle bei der Trennung von Sommer- und Winterformen spielen. Eine Trennung war auch nach Erntejahr und Anbaustandort in allen Fällen deutlich, wo mehrere Teile desselben Sortimentes (Roggen) oder das gesamte Sortiment (Weizen) in mehreren Vergleichsanbauversuchen beschrieben wurden und die gesamten Beschreibungen in die Auswertung einflossen. Diese Trennung zeigt, dass die Umweltfaktoren aber möglicherweise auch die Subjektivität der Bonitur von gewissen qualitativen und halbquantitativen Merkmalen eine begrenzte Vergleichbarkeit von Beschreibungen aus unterschiedlichen Jahren und Standorten ermöglichen. Eine gewisse Variabilität bestimmter Merkmale ist bei abweichenden klimatischen und edaphischen Bedingungen in der Regel zu erwarten [23]. Die relativ starken Unterschiede in den Eigen- schaften der Prüfungsstandorte können dazu beitragen, die jahres- und standortbedingte Gruppierung zu erklären. Außerdem kann sich das quantitative Verhältnis zwischen den Linien innerhalb einer Landsorte unter Einfluss der Witterung und der Standortbedingungen von Jahr zu Jahr verschieben. Das weist darauf hin, dass die gesamten Sortimente gleichzeitig am selben Standort beschrieben werden sollten, um Unterschiede zwischen den Sorten feststellen zu können und eine optimale Evaluierung der Vielfalt zu erzielen.

\section{VIELFALT DER LANDSORTENSORTI- MENTE}

Die Identifizierung möglicher Duplikate in umfangreichen Genbanksammlungen kann allgemein als Ziel betrachtet werden, um unnötige Kosten bei der Sicherung zu vermeiden [24]. Eine Identifizierung auf der einzigen Basis von Passportdaten ist aufgrund von Ungenauigkeiten bei der Datensammlung sowie Änderungen und Kontaminierungen im Laufe der Regeneration besonders schwierig und unzuverlässig [25] [9]. Im Fall vom Roggen, der auf Fremdbefruchtung angewiesen ist, wurde eine genetische Änderung in Genbanksammlungen im Laufe der Zeit bereits bewiesen [26]. Zur Entdeckung der Duplikate ist eine Kombination von molekularbiologischen Methoden, Passportdaten und phänotypischer Charakterisierung empfehlenswert [27]. Aber auch die phänotypische Charakterisierung allein kann wichtige Ergänzungen und Hinweise dazu liefern, besonders wenn der finanzielle Aufwand für die genetischen Analysen nicht vertretbar ist. Bei den vorliegenden Untersuchungen wurde eine gewisse Unähnlichkeit zwischen den wiederholten Beschreibungen der Referenzsorten festgestellt. Sie war im Fall des Sommerweizens Fasan und des Winterweizens Casut im Versuch Eyrs 2004 und im Fall des Winterroggens Cadi im Versuch Fragsburg 2005 auffallend hoch. Wenn die Distanz zwischen den jeweiligen Referenzsorten als Genauigkeitsgrenze der Methode betrachtet wird, sollen alle Landsortenpaare und -gruppen, die untereinander eine niedrigere oder gleiche Distanz als die Referenzsorten aufweisen, als potentielle Duplikate im Sortiment betrachtet werden. Da die Anzahl solcher Fälle eher begrenzt war (eine Gruppe mit 3 Landsorten im Weizensortiment, zwei Gruppen mit 3 bzw. 2 Landsorten im Roggensortiment und 2 Gruppen mit je 2 Sorten im Gerstensortiment), weisen die Ergebnisse der vorliegenden Untersuchungen darauf hin, dass die meisten gesam- melten Landsorten sich voneinander unterscheiden. Darauf deutet auch die breite Streuung mehrerer quantitativer Merkmale bezüglich der Backqualität und der zusätzlichen Inhaltstoffe hin, die in der Berechnung der Diversität nicht berücksichtigt werden konnten, weil sie nicht an allen Landsorten gemessen worden waren. Anhand der Mittelwerte der Euklidischen Distanz der einzelnen Beschreibungen zum Zentroid aller im selben Vergleichsanbau beschriebenen Landsorten zeigte das Teilsortiment von Roggen in Fragsburg 2005 die höchste Vielfalt, während der niedrigste Wert beim Gerstensortiment in Eyrs 2004 vorkam. Der Vergleich der Passportdaten der Landsorten, die untereinander ähnlicher oder genauso ähnlich waren wie die wiederholten Beschreibungen der Referenzen, brachte in einem einzigen Fall eine Bestätigung der Information aus den phänotypischen Daten. Die Sommergerste LHVae013 wurde auf einem Hof in der Gemeinde Unsere Liebe Frau im Walde bereits vor Beginn des Projektes GENE-SAVE gesammelt, während die Landsorte LHVae024 als Verunreinigung in der Saatgutprobe einer Sommerroggenlandsorte (LSCae048) aus demselben Hof stammte und in der Nordtiroler Genbank aus der Probe gereinigt und vermehrt wurde. Alle anderen Landsortenpaare und gruppen wiesen keine Übereinstimmung in der Herkunft auf. So wurden die Sommerweizen LTAae025, LTAae037 und LTAae029 in den Gemeinden Brixen, Aldein bzw. Margreid gesammelt, während im Winterroggensortiment die Landsorten LSC057 LSCO45 und LSCO41 die Gemeinden Mals, Brixen bzw. Altrei als Herkunftsort hatten und das Paar LSC056 und LSC060 in St. Leonhard in Passeier bzw. Martell gesammelt wurde. Da in all diesen Fällen keine räumliche Nähe zwischen den genannten Ortschaften gegeben ist, tragen die Herkünfte der Landsorten zur Erklärung der phänotypischen Ähnlichkeit wenig bei. 


\section{SCHLUSSFOLGERUNGEN}

Die Ergebnisse deuten darauf hin, dass die angewandte Methodik zur Bewertung der Diversität ein Hilfsinstrument sein kann, um vorhandene Duplikate in der Sammlung zu entdecken. Besonders das Vorhandensein von qualitativen Deskriptoren bringt aber gewisse Schwierigkeiten in der Gesamtbewertung. Die phänotypische Beschreibung der Landsorten kann als Ergänzung der genetischen Charakterisierung betrachtet werden. In Fällen, in denen der finanzielle Aufwand für die genetischen Analysen nicht vertretbar ist, stellt die phänotypische Charakterisierung eine mögliche technologiearme Alternative dazu dar. Die endgültige, fundierte Entscheidung über das Vorhandensein von Duplikaten kann allerdings am besten durch die Kombination mehrerer Ansätze (phänotypische und molekularbiologische Untersuchungen) getroffen werden.

Die hohe Vielfalt der untersuchten GetreideSortimente zeigt, dass die Südtiroler Getreide-Landsortensammlung ein wichtiges Genreservoir für die Zukunft darstellt. Die Sicherung der Landsorten ist notwendig, um dieses Gut für die künftigen Generationen zu erhalten.

\section{DANKSAGUNGEN}

Für inhaltliche Anregungen bedanken wir uns bei Peer Schilperoord, Andrea Heistinger, Kaspar Holaus und Christian Partl. Peer Schilperoord stellte das Saatgut der Schweizer Landsorten zur Verfügung. Diese Arbeit wäre ohne die Kooperation zahlreicher Kollegen nicht möglich gewesen. An dieser Stelle möchten wir uns bei den Kollegen der Sektionen Berglandwirtschaft und Alternativkulturen (Elisabeth Werth, Priska Egger, Manuel Pramsohler, Barbara Lantschner, Maria Stolzlechner, Markus Hauser, Joachim Stecher) und vom Bodenlabor des Versuchszentrums Laimburg (Oskar Andreaus, Elmar Stimpfl), beim Personal der Betriebe Mair am Hof, Eyrs, Fragsburg, Laimburg und der Fachschule Salern für die Hilfe bei der Organisation und Durchführung der Feldarbeiten herzlich bedanken. Markus Falk, Gabriele Peratoner und Luigi Cossio lieferten statistische bzw. mathematische Hinweise zur Berechnung der Diversität.

\section{ZUSAMMENFASSUNG}

Die Tätigkeit des Versuchszentrums Laimburg zur Sammlung der noch erhaltenen Landsorten in Südtirol hat zur Entstehung einer relativ umfangreichen Sammlung der wichtigsten Getreidearten der Alpen geführt. Die Erkennung von Duplikaten und die Quantifizierung der Ähnlichkeit zwischen den Landsorten ist eine zentrale Frage, um die Vielfalt der Sortimente bewerten zu können. Im Rahmen des Interreg III A Projektes GENE-SAVE wurden 89 Landsorten phänotypisch beschrieben, die zwischen 1993 und 2008 in Südtirol gesammelt wurden und aktuell in der Genbank des Landes Tirol gesichert sind. Die Bewertung der phänotypischen Vielfalt mit Methoden der beschreibenden Statistik zeigte, dass Beschreibungen aus unterschiedlichen Jahren und/oder Standorten untereinander nicht vergleichbar sind. Die phänotypische Charakterisierung der Sortimente sollte daher an einem einzigen Standort in einem einzigen Jahr erfolgen. Bei der Betrachtung der Ergebnisse einzelner Versuche wurde eine relativ hohe Diversität mit nur wenigen möglichen Duplikaten gefunden. Nur in einem Fall konnten die Passportdaten das Vorkommen der Duplikate erklären. Dank ihrer Vielfalt stellen die Landsorten ein wichtiges Genreservoir für die Zukunft dar. Die phänotypische Beschreibung kann die Informationen der genetischen Charakterisierung ergänzen oder eine „technologiearme“ Alternative darstellen.

\section{RIASSUNTO}

Le attività del Centro di Sperimentazione Laimburg svolte alla raccolta delle varietà locali ancora presenti in Alto Adige hanno condotto alla costituzione di una collezione relativamente numerosa delle principali specie cerealicole tipiche delle Alpi. L'identificazione di duplicati e la quantificazione del grado di somiglianza tra le varietà locali rappresenta un aspetto fondamentale per poter valutare la diversità delle collezioni. Nell'ambito del progetto Interreg III A GENE-SAVE 89 varietà locali di frumento, segale, orzo ed avena raccolte in Alto Adige tra il 1993 e il 2008 e conservate attualmente nella banca del germoplasma del Tirolo sono state descritte dal punto di vista fenotipico. La valutazione statistica della diversità fenotipica mediante metodi della statistica descrittiva ha evidenziato che descrizioni effettuate in anni e/o località differenti non sono confrontabili tra loro. Per questo motivo si conclude che la descrizione fenotipica dell'intera collezione di una data specie dovrebbe essere effettuata in un unico anno nella stessa località. I risultati delle singole prove comparative mostrano l'esistenza di un livello di diversità relativamente elevato all'interno delle collezioni delle singole specie, con un numero limitato di possibili duplicati. In un unico caso è stato possibile spiegare la presenza dei duplicati sulla base dei dati di passaporto. Grazie alla loro diversità le varietà locali rappresentano un'importante riserva genetica per il futuro. La descrizione fenotipica rappresenta un utile complemento alla caratterizzazione genetica od un'opzione alternativa a ridotto contenuto tecnologico. 


\section{LITERATUR}

[1] Zohary D. (2002). Unconscious selection in plants under domestication. In: Knüpffer $\mathrm{H}$. Ochsmann J. (eds.). Rudolf Mansfeld and plant genetic resources. (Schriften zu genetischen Ressourcen; 22). ZADI, Bonn, Deutschland, pp. 121-128.

[2] Lorenzetti S., Falcinelli M. (2006). Varietà e dintorni. Dal Seme 1, 19-29.

[3] Marchal L. (1929). Tirols Pflanzenbau. Wiener Landwirtschaftliche Zeitung 79, 123-128.

[4] Mayr E. (1934). Die Bedeutung der alpinen Getreidelandsorten für die Pflanzenzüchtung und Stammesforschung mit besonderer Beschreibung der Landsorten in Nordtirol und Vorarlberg. Zeitschrift für Züchtung A: Pflanzenzüchtung 19, 195-228.

[5] Zeven A.C. (1998). Landraces. A review of definitions and classifications. Euphytica 104, 127-139, DOI: 10.1023/A:1018683119237.

[6] Zeven A.C. (1999). The traditional inexplicable replacement of seed and seed ware of landraces and cultivars. A review. Euphytica 110, 181-191 DOI: 10.1023/A:1003701529155.

[7] Lehmann C.O. (1981). Collecting European land-races and development of European gene banks - historical remarks. Die Kulturpflanze 29, 29-40, DOI: 10.1007/BF02014732.

[8] Wetzel M. (1986). Roggen (Secale cereale). In: Oehmischen J. (ed.). Pflanzenproduktion. Bd. 2: Produktionstechnik. Verlag Paul Parey, Berlin, Hamburg, Deutschland, pp. 308-332.

[9] Zeven A.C. (1996). Results of activities to maintain landraces and other material in some European countries in situ before 1945 and what we may learn from them. Genetic Resources and Crop Evolution 43, 337-341, DOI: 10.1007/BF00132953.

[10] von Bothmer R., van Hintum T.J.L., Knüpffer H. et al. (2002). Diversity in Barley (Hordeum vulgare). In: Knüpffer H., Ochsmann J. (eds.). Rudolf Mansfeld and plant genetic resources. Proceedings of a symposium dedicated to the 100th birthday of Rudolf Mansfeld, Gatersleben, Germany, 8-9 October 2001. (Schriften zu genetischen Ressourcen; 22). ZADI, Bonn, Deutschland, pp. 129-136.
[11] Harlan J.R. (1975). Our vanishing genetic resources. Science 188, 618-621, DOI: 10.1126/science.188.4188.617.

[12] Toma R. (1933). Ergebnisse der Getreideschlacht im Alto Adige. Landwirtschaftlicher Kalender, pp. 52-59.

[13] Holaus K., Köck L. (1989). Landsortensammlung der Landesanstalt für Pflanzenzucht und Samenprüfung in Rinn. In: Köck L., Holaus K. (eds.). 50 Jahre Landesanstalt für Pflanzenzucht und Samenprüfung in Rinn 1939-1989. Rinn, Österreich, pp.187-197.

[14] Schachl R. (1981). Cereal land-races from Austria and their utilization in plant breeding. Die Kulturpflanze 29, 99-110, DOI: $10.1007 /$ BF02014740.

[15] Schilperoord P. (2007). Die Vielfalt der Weizen- und Gerstelandsorten Graubündens. Jahresbericht der Naturforschenden Gesellschaft Graubünden 113, 5-28.

[16] Hidalgo R. (2003). Variabilidad genética y caracterización de especies vegetales. In: Franco T. L., Hidalgo R. (eds.). Análisis estadístico de datos de caracterización morfológica de recursos filogenéticos. (Boletin tecnico IPGRI; 8). Instituto Internacional de Recursos Filogeneticos, Cali, Kolumbien, pp. 2-26.

[17] Meier U. (1997). Growth stages of monoand dicotyledonous plants. $\mathrm{BBCH}$-monograph. Blackwell Wissenschafts-Verlag, Berlin, Wien, Deutschland, Österreich.

[18] ISTA (1996). International Rules for Seed Testing. Rules 1996. Seed Science \& Technology 24, 1-342.

[19] Camussi A., Möller F., Ottaviano E. et al. (1986). Metodi statistici per la sperimentazione biologica. Zanichelli, Bologna, Italien.

[20] Feoli E., Lagonegro M., Zampar A. (1982). Classificazione e ordinamento della vegetazione. Metodi e programmi di calcolo. C.N.R., Udine, Italien.

[21] Cole-Rodgers P., Smith D.W., Bosland P.W. (1997). A novel statistical approach to analyze genetic resource evaluations using Capsicum as an example. Crop Science 37 (3), 1000-1002, DOI: 10.2135/crop$\underline{\text { sci1997.0011183X003700030050x. }}$
[22] Dreisigacker S., Zhang P., Warburton M.L. et al. (2005). Genetic diversity among and within CIMMYT wheat landrace accessions investigated with SSRs and implications for plant genetic resources management. Crop Science 45 (2), 653-661, DOI: $10.2135 /$ cropsci2005.0653.

[23] Milatz R. (1970). Kriterien der Getreidearten einschließlich Mais und ihre Bewertung zur Sortenidentifizierung. Verband Deutscher Pflanzenzüchter e.V., Bonn, Deutschland.

[24] Pardey P.G., Koo B., Wright B.D. et al. (2001). Costing the conservation of genetic resources. CIMMYT's ex situ maize and wheat collection. Crop Science 41 (4), 12861299, DOI: $10.2135 /$ cropsci2001.4141286x.

[25] van Hintum T.J.L., Knüpffer H. (1995). Duplication within and between germplasm collections. I. Identifying duplication on the basis of passport data. Genetic Resources and Crop Evolution 42 (2), 127-133, DOI: $10.1007 /$ BF02539516.

[26] Chebotar S., Röder M.S., Korzun V. et al. (2003). Molecular studies on genetic integrity of open-pollinating species rye (Secale cereale L.) after long-term genebank maintenance. Theoretical and Applied Genetics 107, 1469-1476, DOI: 10.1007/s00122-003-1366-1.

[27] Dobrovolskaya O., Saleh U., Malysheva-Otto L. et al. (2005). Rationalising germplasm collections: a case study for wheat. Theoretical and Applied Genetics 111 (7), 1322-1329, DOI: 10.1007/s00122-005-0061-9. 
ANHANG 1: ABBILDUNGEN

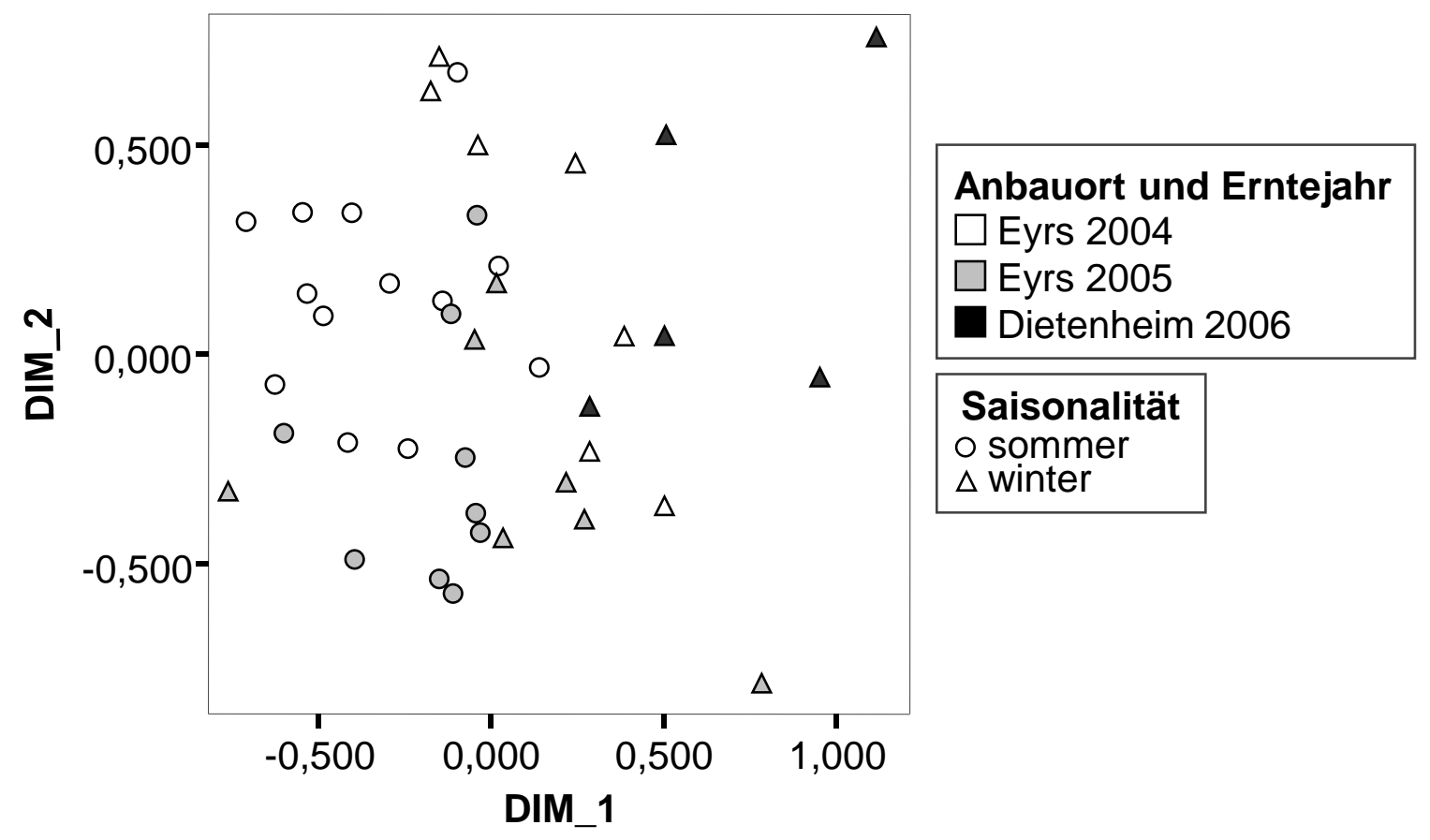

Abb. 1: Zweidimensionales Streudiagramm aus der multidimensionalen Skalierung der phänotypischen Beschreibungen des Weizensortiments. Die Daten wurden an zwei Standorten in drei Beobachtungsjahren erhoben. // Two-dimensional scatterplot originated by the multidimensional scaling of the phenotypic descriptions of the wheat collection. Data were collected at two sites during three observation years. 


\section{Rescaled Distance Cluster Combine}

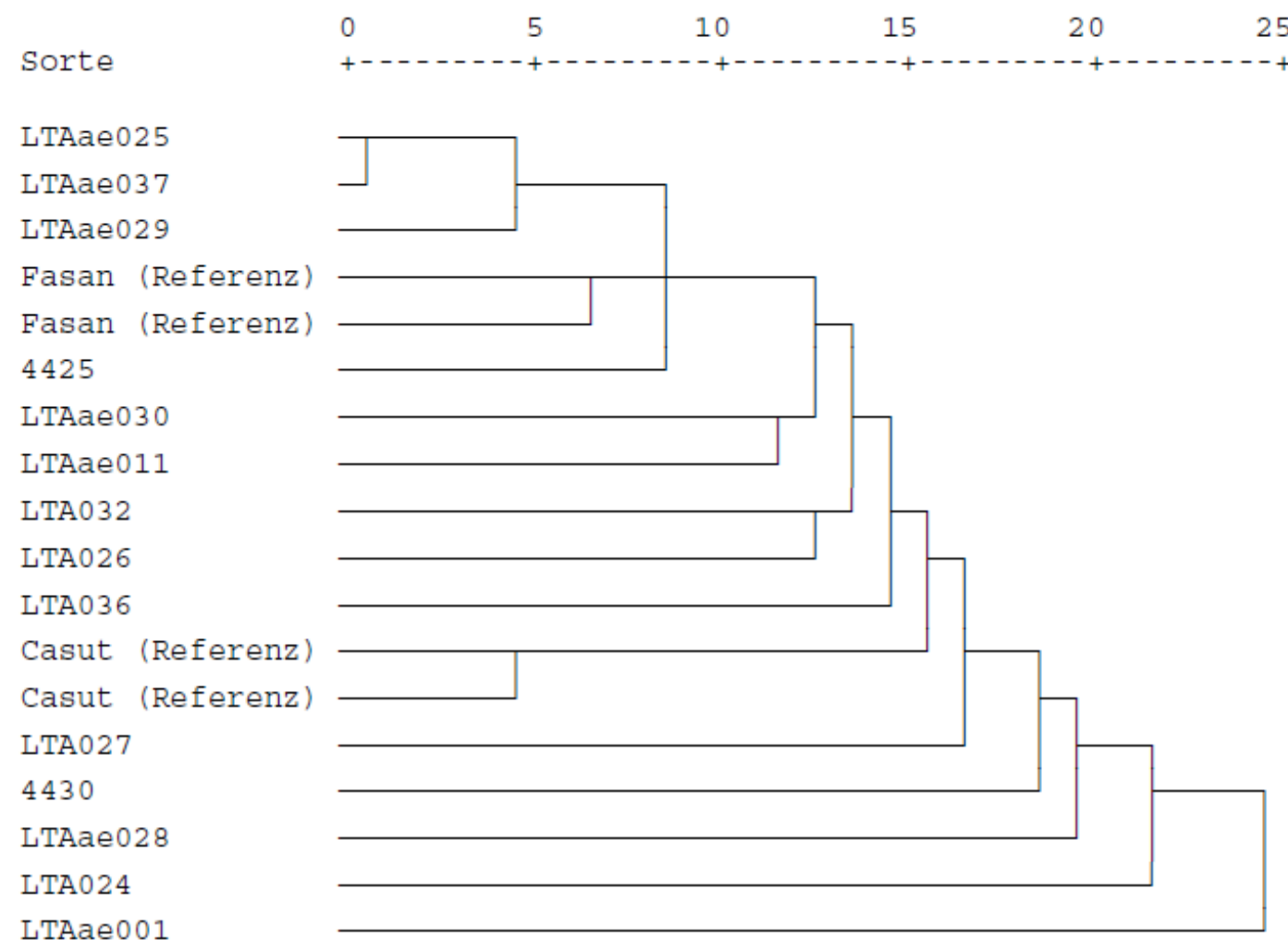

Abb. 2 Hierarchische Clusterstruktur der phänotypisch beschriebenen Sommer- und Winterweizenlandsorten (Standort Eyrs, Erntejahr 2004). Unähnlichkeitsmaß = Euklidische Distanz, Clusterverfahren = nächstgelegener Nachbar (single linkage). // Hierarchical clustering structure of the phenotypically described spring and winter wheat landraces (site Eyrs, harvest year 2004). Diversity measure $=$ Euclidean distance, cluster method $=$ single linkage. 


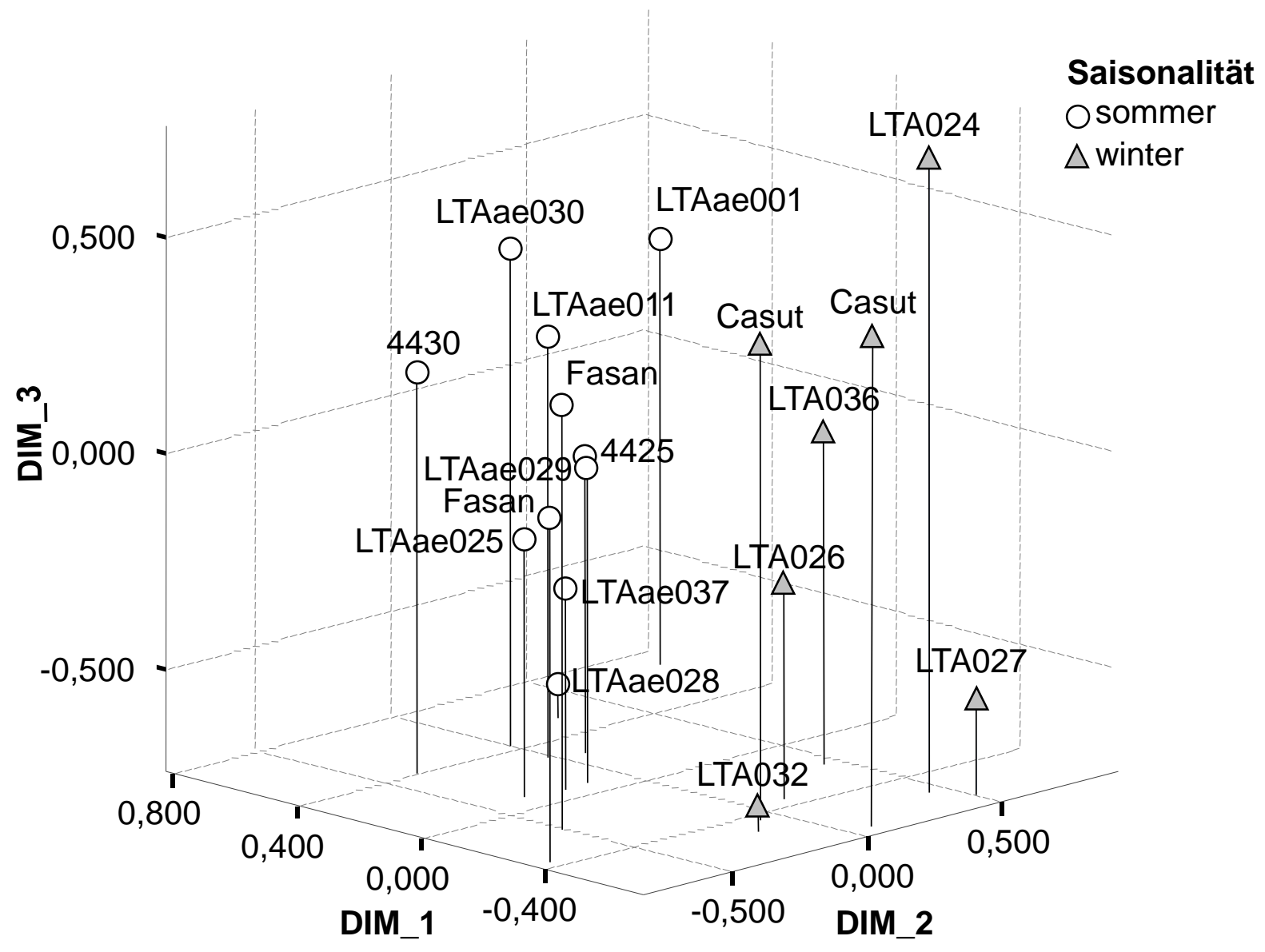

Abb. 3: Streudiagramm aus der multidimensionalen Skalierung der phänotypischen Beschreibungen des Weizensortiments am Standort Eyrs im Jahr 2004. Fasan und Casut sind die Referenzsorten für die Sommer- bzw. für die Winterform. // Scatterplot originated by the multidimensional scaling of the phenotypic descriptions of the winter wheat collection at the site Eyrs in 2004. Fasan and Casut are the reference varieties for the summer and the winter form respectively. 


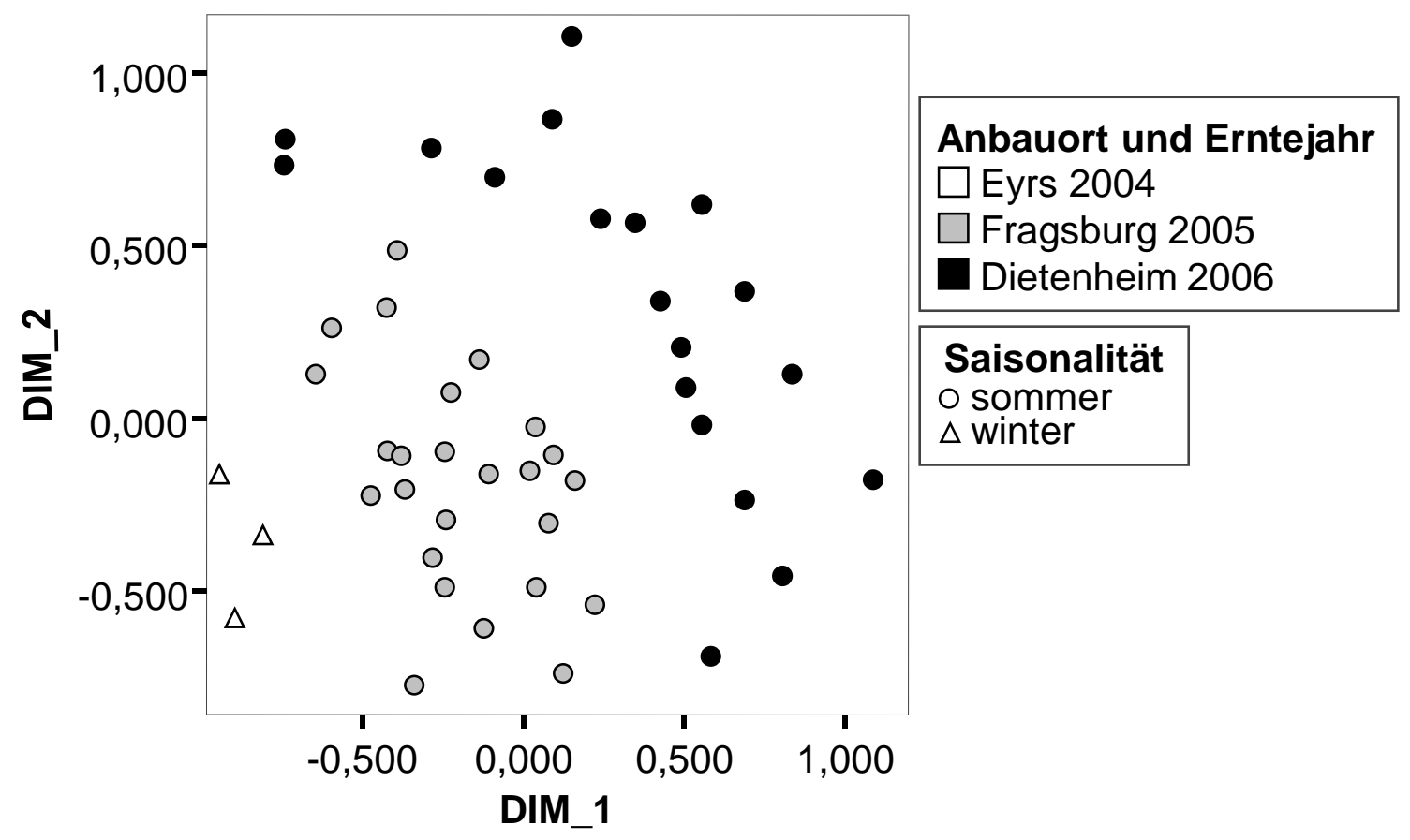

Abb. 4: Zweidimensionales Streudiagramm aus der multidimensionalen Skalierung der phänotypischen Beschreibungen des Roggensortiments. Die Daten wurden an drei Standorten in drei Beobachtungsjahren erhoben. // Two-dimensional scatterplot originated by the multidimensional scaling of the phenotypic descriptions of the rye collection. Data were collected at three sites during three observation years. 


\section{Rescaled Distance Cluster Combine}

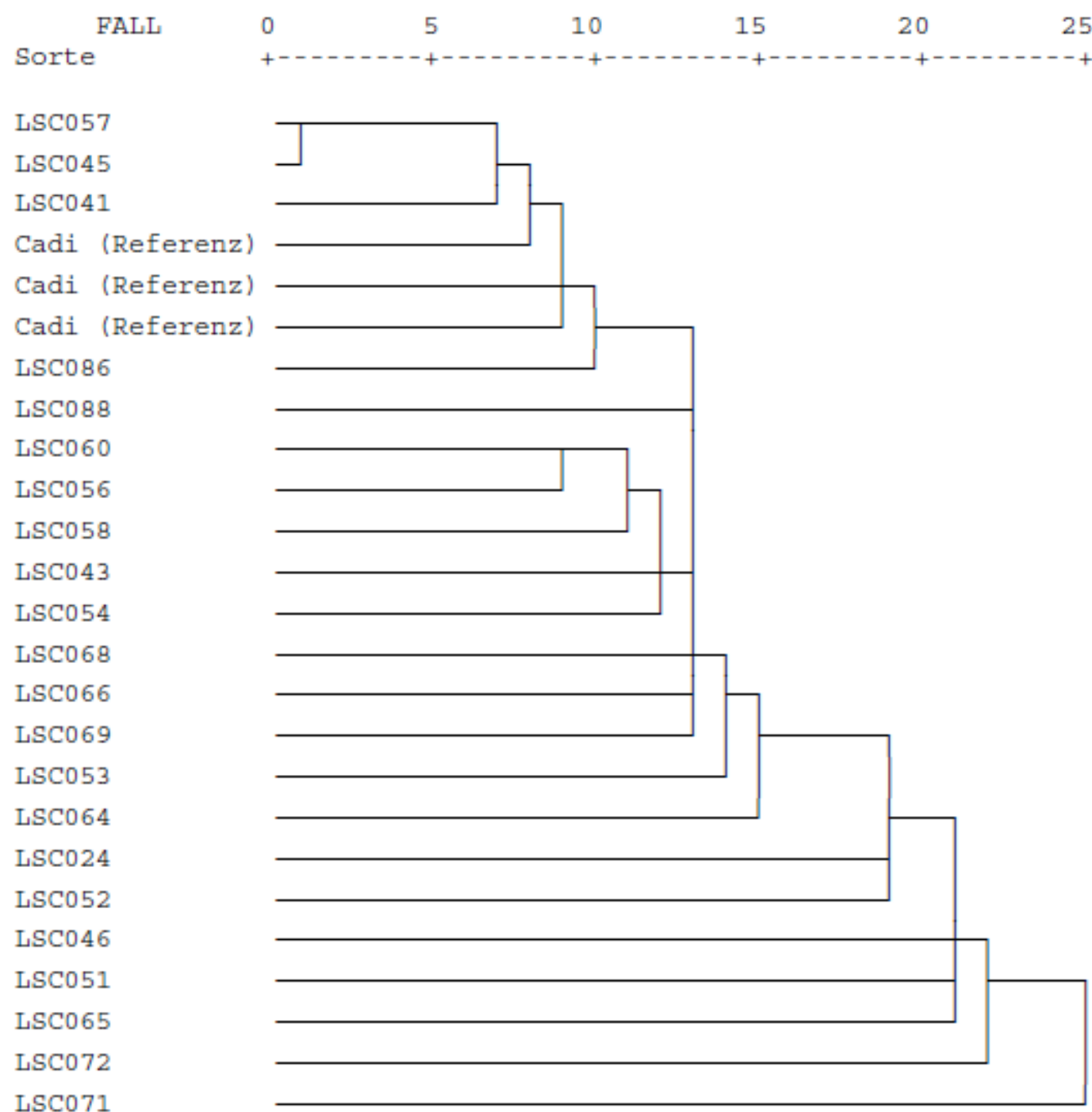

Abb. 5: Hierarchische Clusterstruktur der phänotypisch beschriebenen Winterroggenlandsorten (Standort Fragsburg, Erntejahr 2005). Unähnlichkeitsmaß = Euklidische Distanz, Clusterverfahren = nächstgelegener Nachbar (single linkage). // Hierarchical clustering structure of the phenotypically described winter rye landraces (site Fragsburg, harvest year 2005). Diversity measure $=$ Euclidean distance, cluster method $=$ single linkage. 


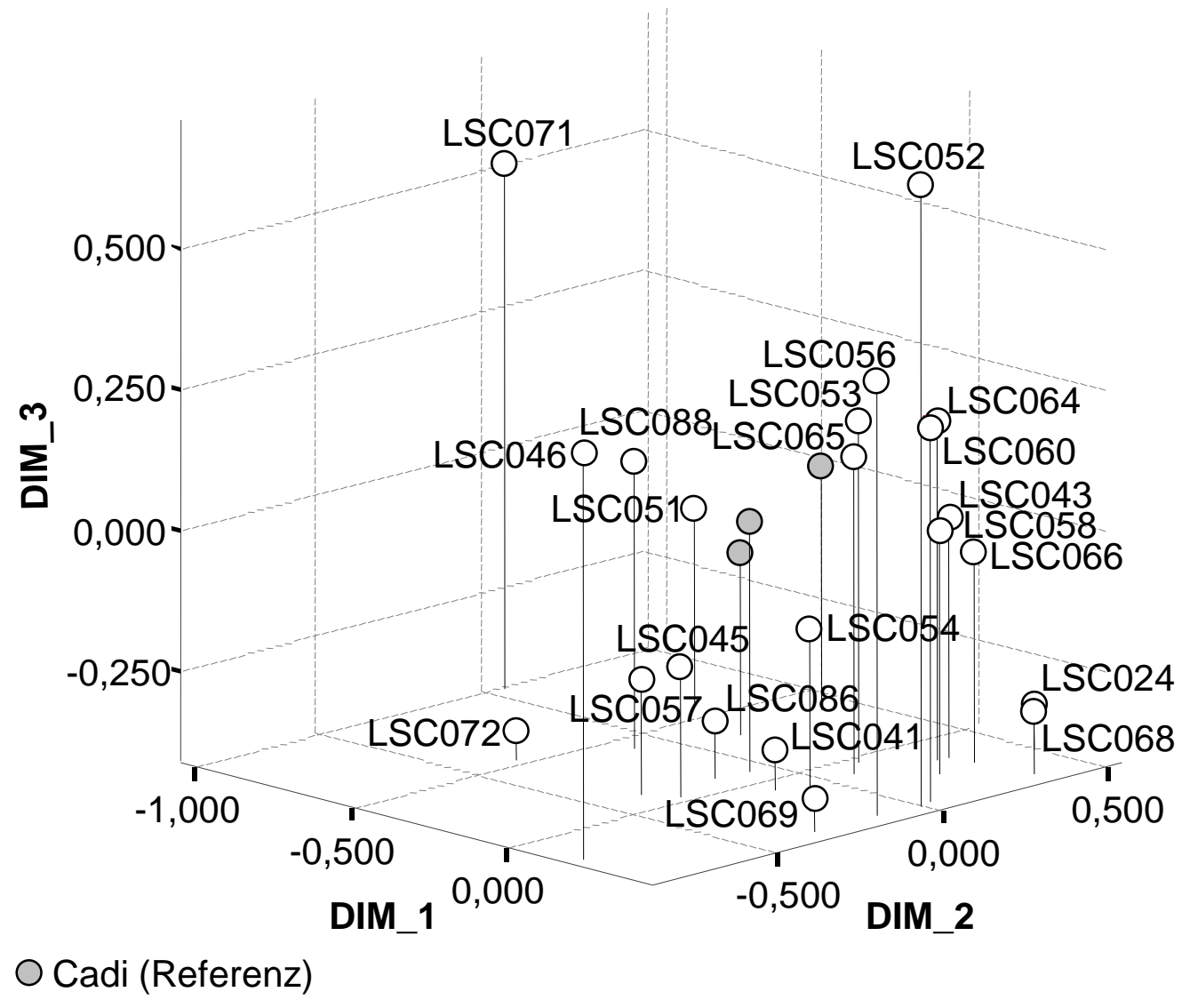

Abb. 6: Streudiagramm aus der multidimensionalen Skalierung der phänotypischen Beschreibungen von 22 Winterroggenlandsorten am Standort Fragsburg im Jahr 2005. // Scatterplot originated by the multidimensional scaling of the phenotypic descriptions of 22 winter rye landraces at the site Fragsburg in 2005. 


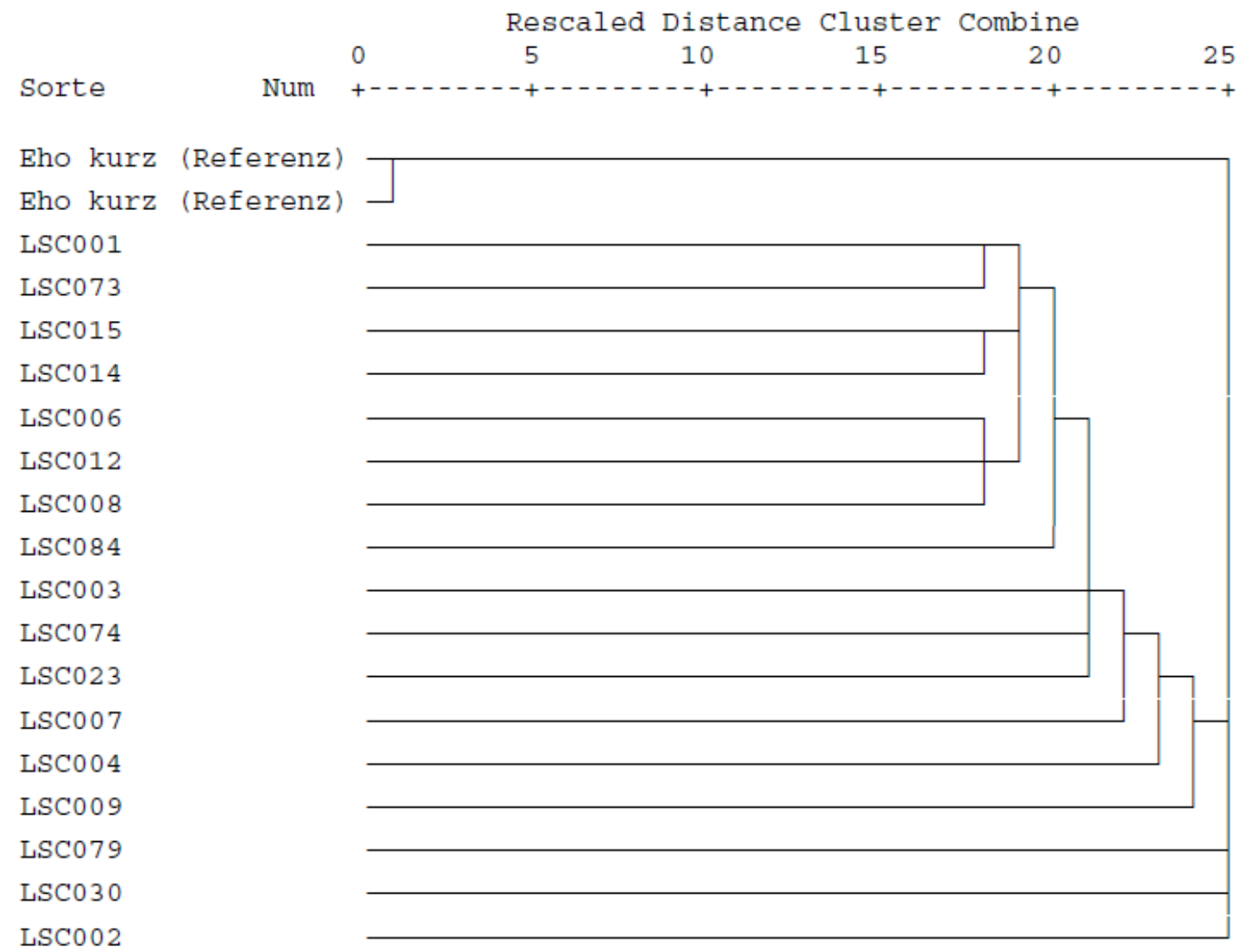

Abb. 7: Hierarchische Clusterstruktur der phänotypisch beschriebenen Winterroggensorten (Standort Dietenheim, Erntejahr 2006). Unähnlichkeits$\mathrm{ma}$ = Euklidische Distanz, Clusterverfahren = nächstgelegener Nachbar (single linkage). // Hierarchical clustering structure of the phenotypically described winter rye landraces (site Dietenheim, harvest year 2006). Diversity measure $=$ Euclidean distance, cluster method $=$ single linkage 


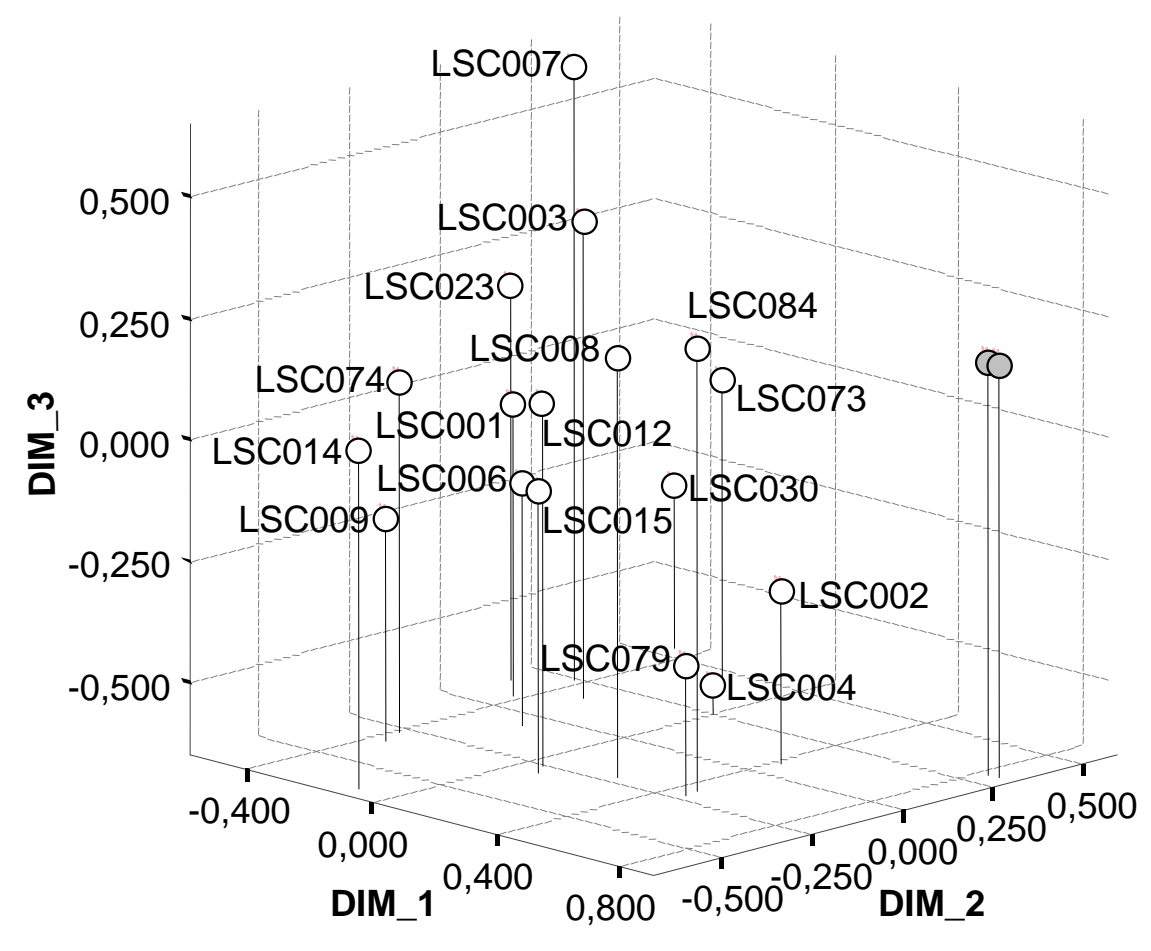

O Eho kurz (Referenz)

Abb. 8: Streudiagramm aus der multidimensionalen Skalierung der phänotypischen Beschreibungen von 17 Winterroggenlandsorten am Standort Dietenheim im Jahr 2006. // Scatterplot originated by the multidimensional scaling of the phenotypic descriptions of 17 winter rye landraces at the site Dietenheim in 2006. 


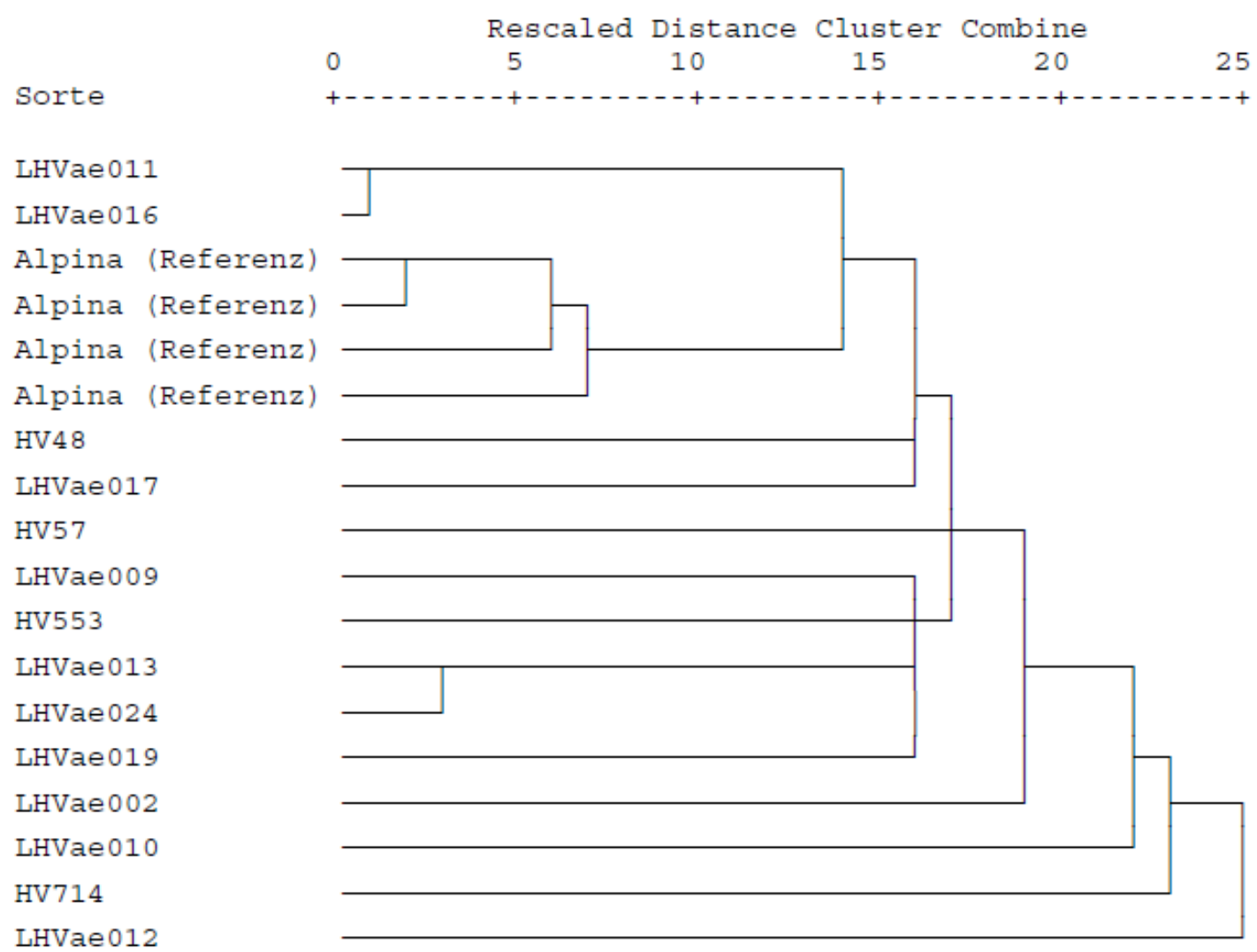

Abb. 9: Hierarchische Clusterstruktur des phänotypisch beschriebenen Sommergerstensortiments (Standort Eyrs, Erntejahr 2004). Unähnlichkeits$\mathrm{ma}=$ = Euklidische Distanz, Clusterverfahren = nächstgelegener Nachbar (single linkage). // Hierarchical clustering structure of the phenotypically described spring barley landraces (site Eyrs, harvest year 2004). Diversity measure = Euclidean distance, cluster method = single linkage. 


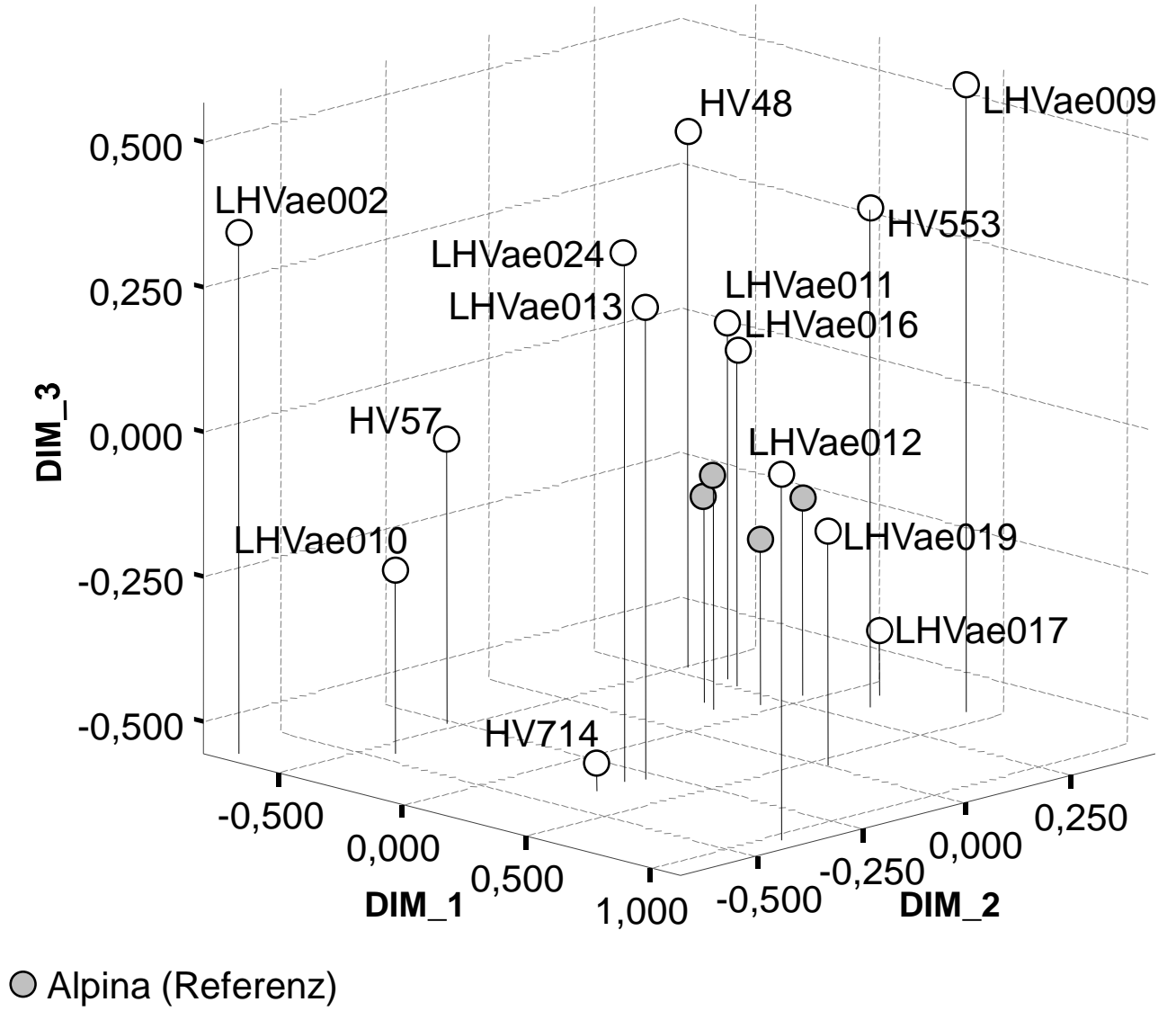

Abb. 10: Dreidimensionales Streudiagramm aus der multidimensionalen Skalierung der phänotypischen Beschreibungen des Sommergerstensortiments am Standort Eyrs im Jahr 2004. // Scatterplot originated by the multidimensional scaling of the phenotypic descriptions of the spring barley collection at the site Eyrs in 2004. 


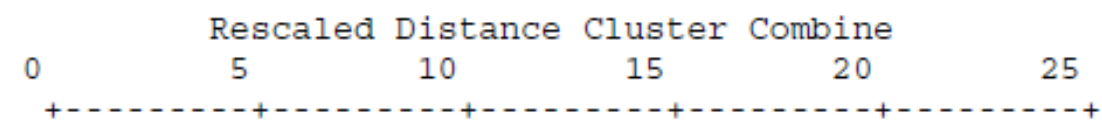

Sorte

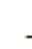

Expander (Referenz)

Expander (Referenz)

Expander (Referenz)

Expander (Referenz)

LASO 20

LASO 05

LASO 29

LASO 04

LAS0 15

LAS 027

LASO 00

LAS0 18

LAS008

LASO 02

LASO 22

LASO0 06

LASO 28

LAS 016

LASO 31

LASO 30

LASO 21

LAS 017

LASO 03

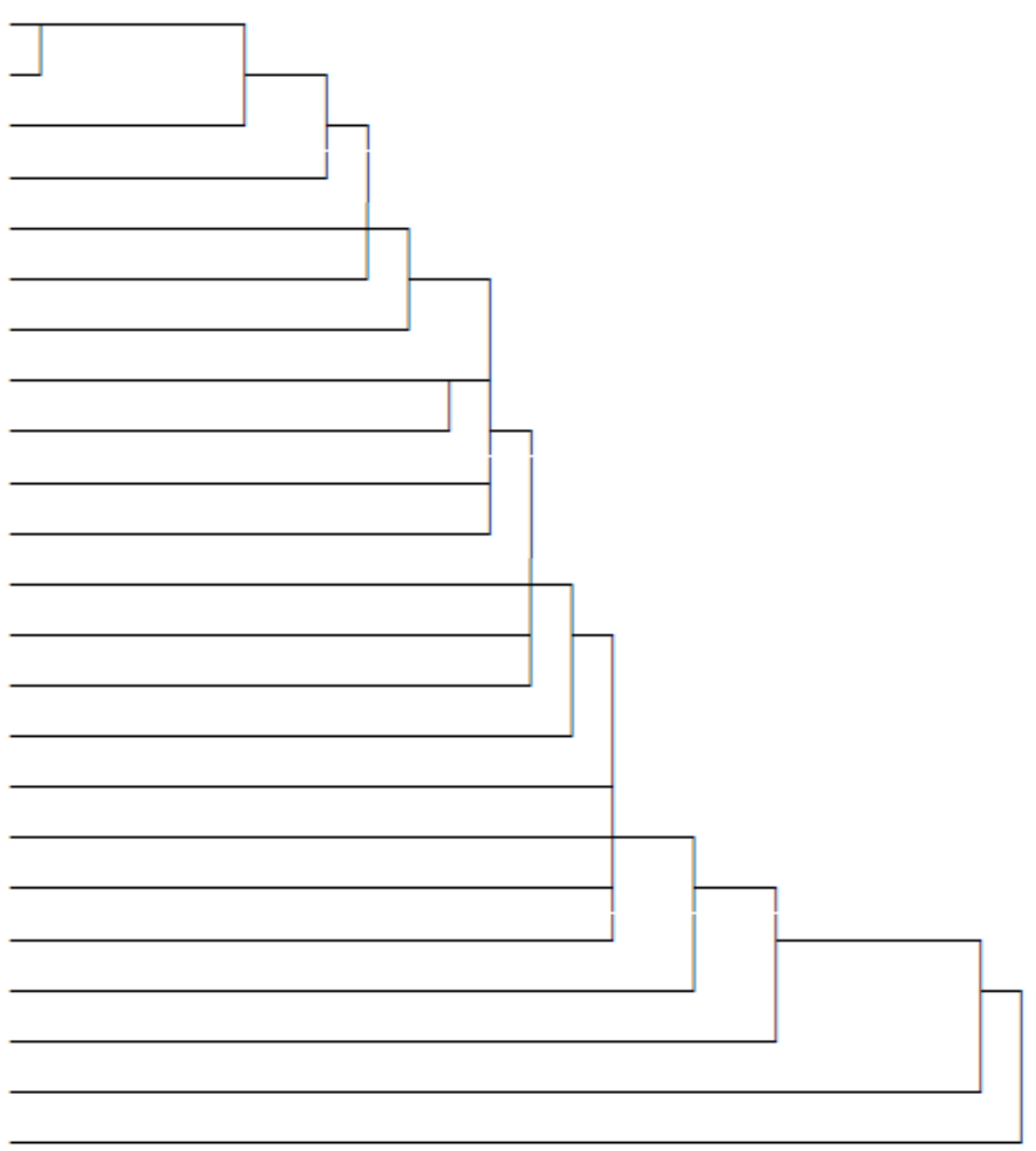

Abb. 11: Hierarchische Clusterstruktur des phänotypisch beschriebenen Hafersortiments (Standort Eyrs, Erntejahr 2005). Unähnlichkeitsmaß = Euklidische Distanz, Clusterverfahren = nächstgelegener Nachbar (single linkage). // Hierarchical clustering structure of the phenotypically described oat landraces (site Eyrs, harvest year 2005). Diversity measure = Euclidean distance, cluster method = single linkage . 
Vielfalt der Südtiroler Getreidelandsorten

02/2020 Laimburg Journal

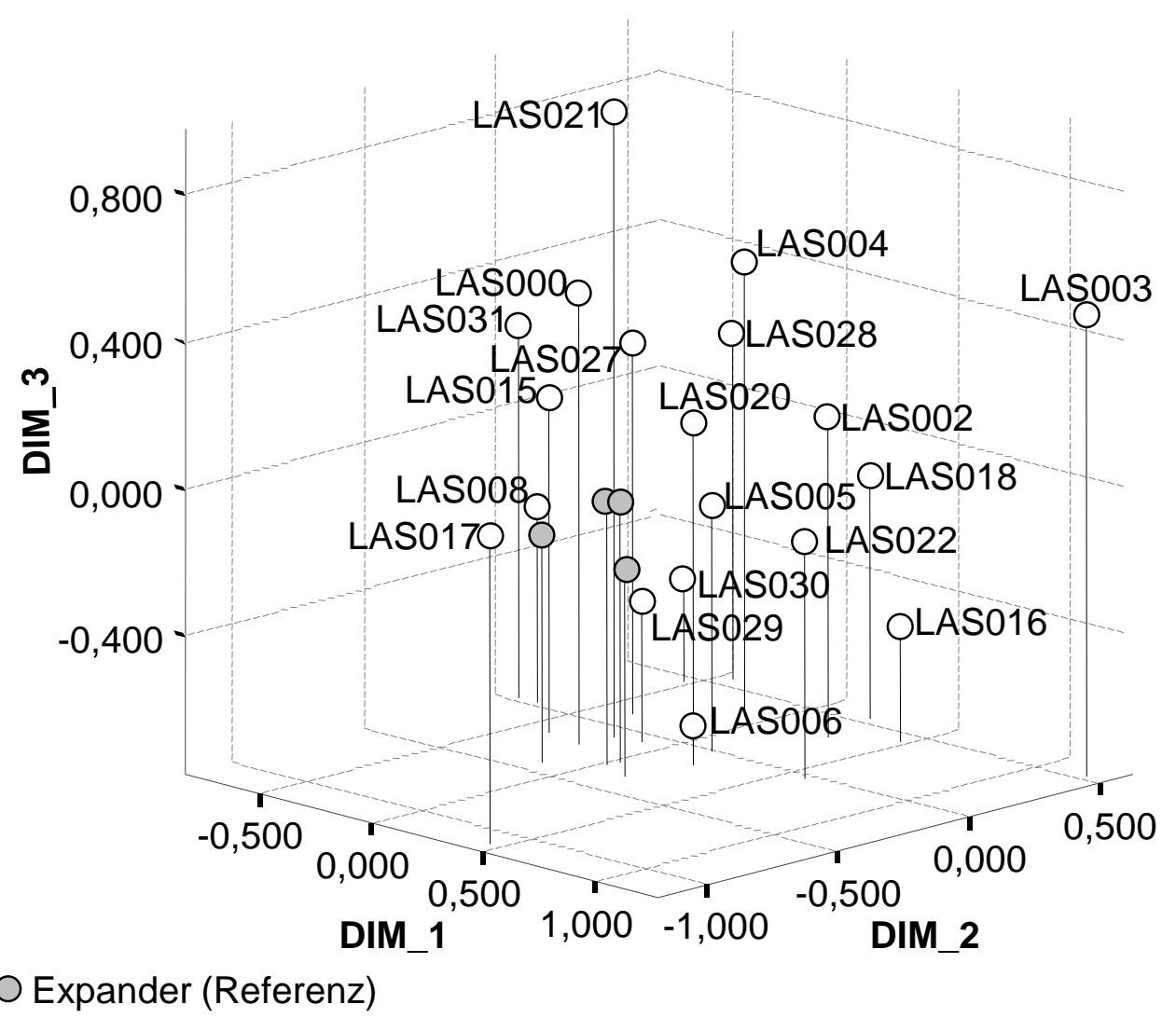

Abb. 12: Dreidimensionales Streudiagramm aus der multidimensionalen Skalierung der phänotypischen Beschreibungen des Hafersortiments am Standort Eyrs im Jahr 2005. // Scatterplot originated by the multidimensional scaling of the phenotypic descriptions of the oat collection at the site Eyrs in 2005.

19 


\section{ANHANG 2: TABELLEN}

Tab. 1: Wetterdaten aus den Wetterstationen vom Versuchszentrum Laimburg an den Anbaustandorten // Meteorological data from weather stations run by the Laimburg Research Centre at the experimental sites.

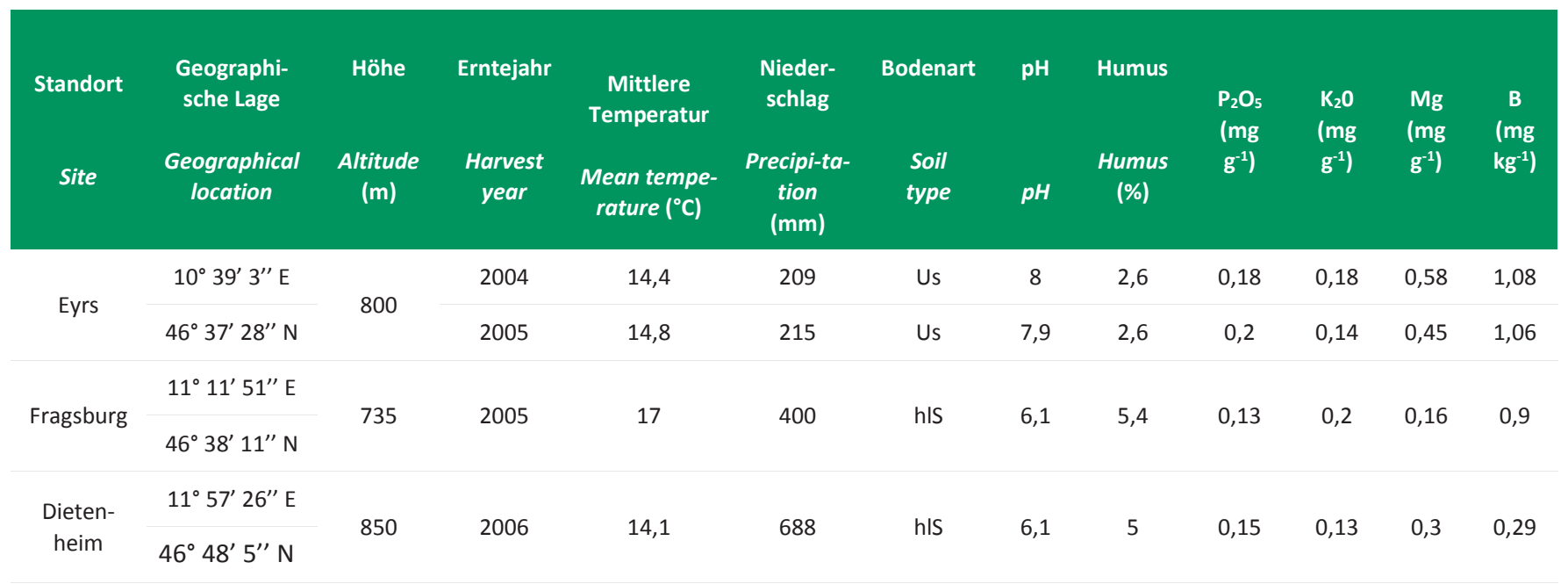


Tab. 2: Anbau- und Erntedetails der Versuche // Cultivation and harvest details of the trials.

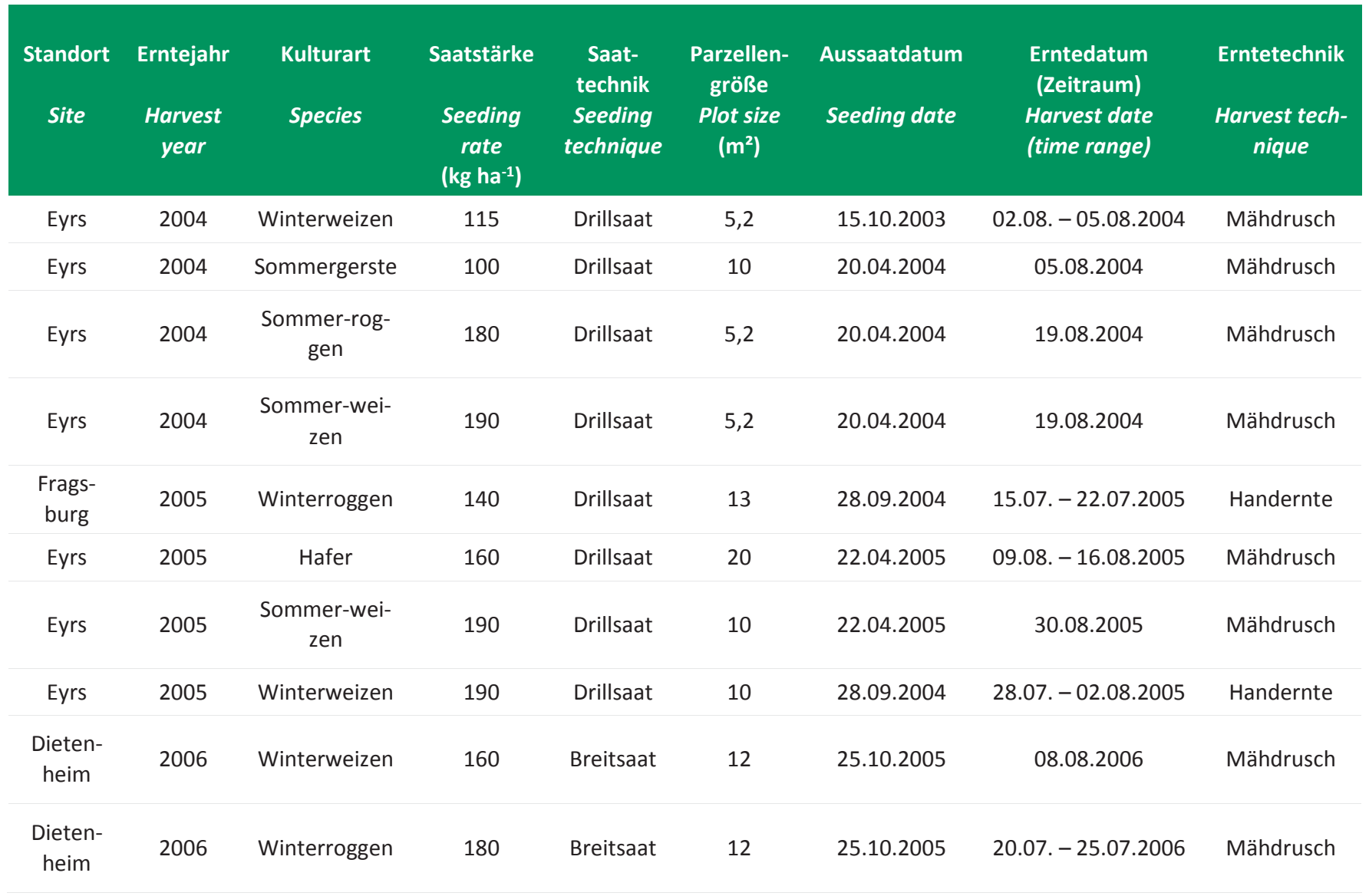


Tab. 3: Anzahl und Typ der verwendeten Deskriptoren und Anzahl der Bonitur- und Aufnahmezeitpunkte über die Vegetationsperiode // Number and type of the descriptors used and number of assessment dates over the growing season.

\begin{tabular}{|c|c|c|c|c|}
\hline \multirow{2}{*}{$\begin{array}{l}\text { Deskriptoren } \\
\text { Descriptors }\end{array}$} & \multicolumn{4}{|c|}{$\begin{array}{l}\text { Kulturart } \\
\text { Species }\end{array}$} \\
\hline & $\begin{array}{l}\text { Weizen } \\
\text { Wheat }\end{array}$ & $\begin{array}{l}\text { Roggen } \\
\text { Rye }\end{array}$ & $\begin{array}{l}\text { Gerste } \\
\text { Barley }\end{array}$ & $\begin{array}{c}\text { Hafer } \\
\text { Oat }\end{array}$ \\
\hline Qualitativ (Anzahl) & 12 & 8 & 10 & 9 \\
\hline Halbquantitativ (Anzahl) & 10 & 15 & 11 & 18 \\
\hline Quantitativ (Anzahl) & 11 & 13 & 7 & 8 \\
\hline Gesamtanzahl & 33 & 36 & 29 & 35 \\
\hline $\begin{array}{l}\text { Anzahl der für die Bonitur/Aufnahme be- } \\
\text { rücksichtigten Entwicklungsstadien }\end{array}$ & 10 & 10 & 9 & 8 \\
\hline
\end{tabular}


Tab. 4: Beschreibung der Datensätze, welche für die Bewertung der phänotypischen Vielfalt verwendet wurden // Description of the data sets used for the assessment of the phenotypic variability.

\begin{tabular}{|c|c|c|c|}
\hline Kulturart & $\begin{array}{l}\text { Verwendete Datensätze } \\
\text { (Anbauort und Erntejahr) }\end{array}$ & Wegen Unvollständigkeit nicht verwendete Merkmale & Ziel der statistischen Analyse \\
\hline Species & $\begin{array}{l}\text { Data sets used (cutivation } \\
\text { site and harvest year) }\end{array}$ & Traits not used because of their incompleteness & Aim of the statistical analysis \\
\hline Weizen & $\begin{array}{l}\text { Eyrs } 2004 \\
\text { Fragsburg } 2005 \\
\text { Dietenheim } 2006\end{array}$ & Hektolitergewicht & $\begin{array}{l}\text { Bewertung der Wiederholbar- } \\
\text { keit und Vergleichbarkeit phä- } \\
\text { notypischer Beschreibungen } \\
\text { aus unterschiedlichen Standor- } \\
\text { ten und Jahren }\end{array}$ \\
\hline Weizen & Eyrs 2004 & Datum Mitte Ährenschieben & $\begin{array}{l}\text { Identifizierung von Duplikaten; } \\
\text { Bewertung der Vielfalt }\end{array}$ \\
\hline \multirow{4}{*}{ Roggen } & \multirow{4}{*}{$\begin{array}{l}\text { Eyrs } 2004 \\
\text { Fragsburg } 2005 \\
\text { Dietenheim } 2006\end{array}$} & Bestockungskapazität & \multirow{4}{*}{$\begin{array}{l}\text { Bewertung der Wiederholbar- } \\
\text { keit und Vergleichbarkeit phä- } \\
\text { notypischer Beschreibungen } \\
\text { aus unterschiedlichen Standor- } \\
\text { ten und Jahren }\end{array}$} \\
\hline & & Datum Mitte Blüte & \\
\hline & & Ährenbreite & \\
\hline & & Schwarzrostbefall & \\
\hline \multirow{4}{*}{ Roggen } & \multirow{4}{*}{ Fragsburg 2005} & Bestockungskapazität & \multirow{4}{*}{$\begin{array}{l}\text { Identifizierung von Duplikaten; } \\
\text { Bewertung der Vielfalt }\end{array}$} \\
\hline & & Datum Mitte Blüte & \\
\hline & & Ährenbreite & \\
\hline & & Schwarzrostbefall & \\
\hline Roggen & Dietenheim 2006 & & $\begin{array}{l}\text { Identifizierung von Duplikaten; } \\
\text { Bewertung der Vielfalt }\end{array}$ \\
\hline Gerste & Eyrs 2004 & & $\begin{array}{l}\text { Identifizierung von Duplikaten; } \\
\text { Bewertung der Vielfalt }\end{array}$ \\
\hline Hafer & Eyrs 2005 & & $\begin{array}{l}\text { Identifizierung von Duplikaten; } \\
\text { Bewertung der Vielfalt }\end{array}$ \\
\hline
\end{tabular}




\section{ANHANG 3: BESCHRIEBENE LANDSORTEN}
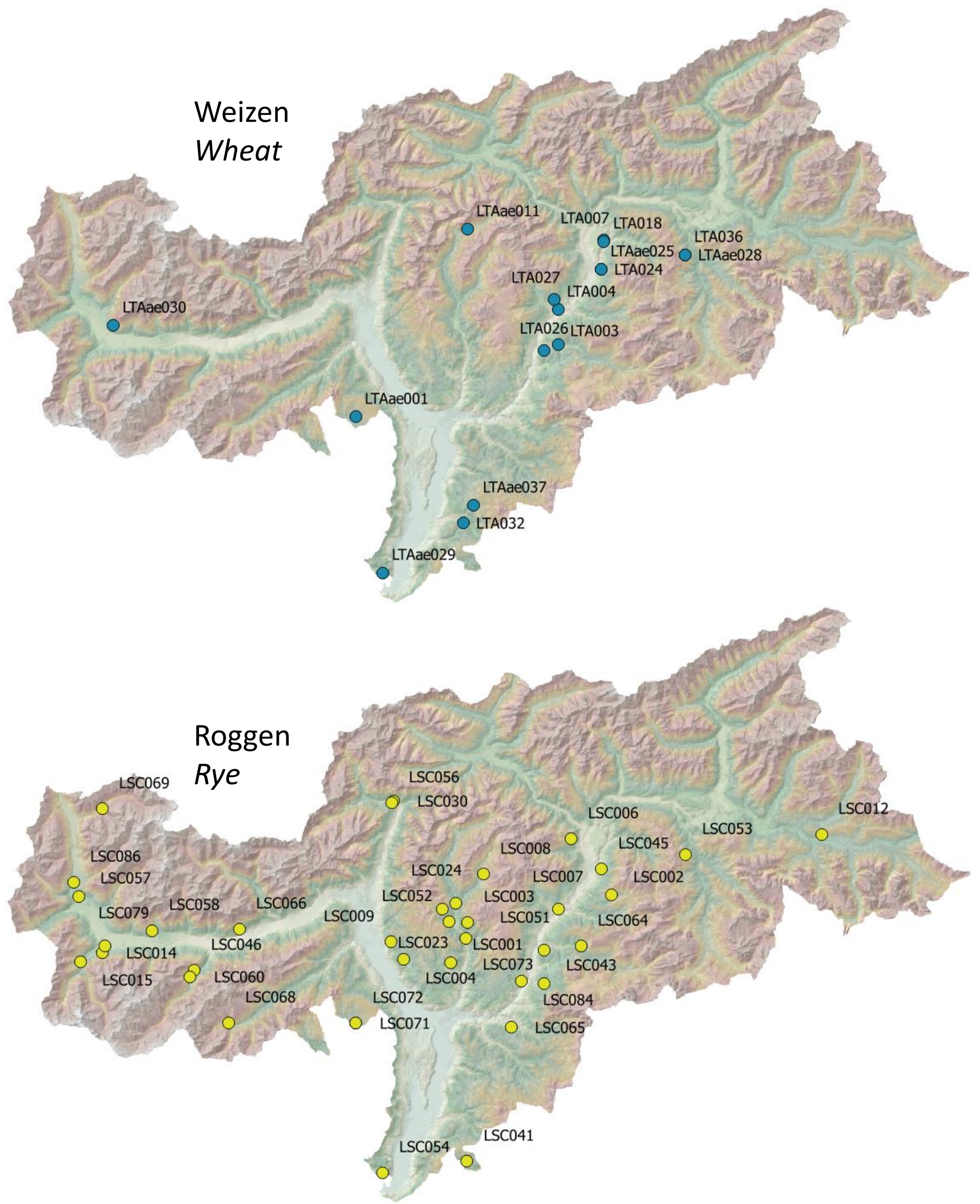

Abb. 13: Herkunft der beschriebenen Weizen- und, Roggenlandsorten // Provenance of the described wheat and rye landraces. 


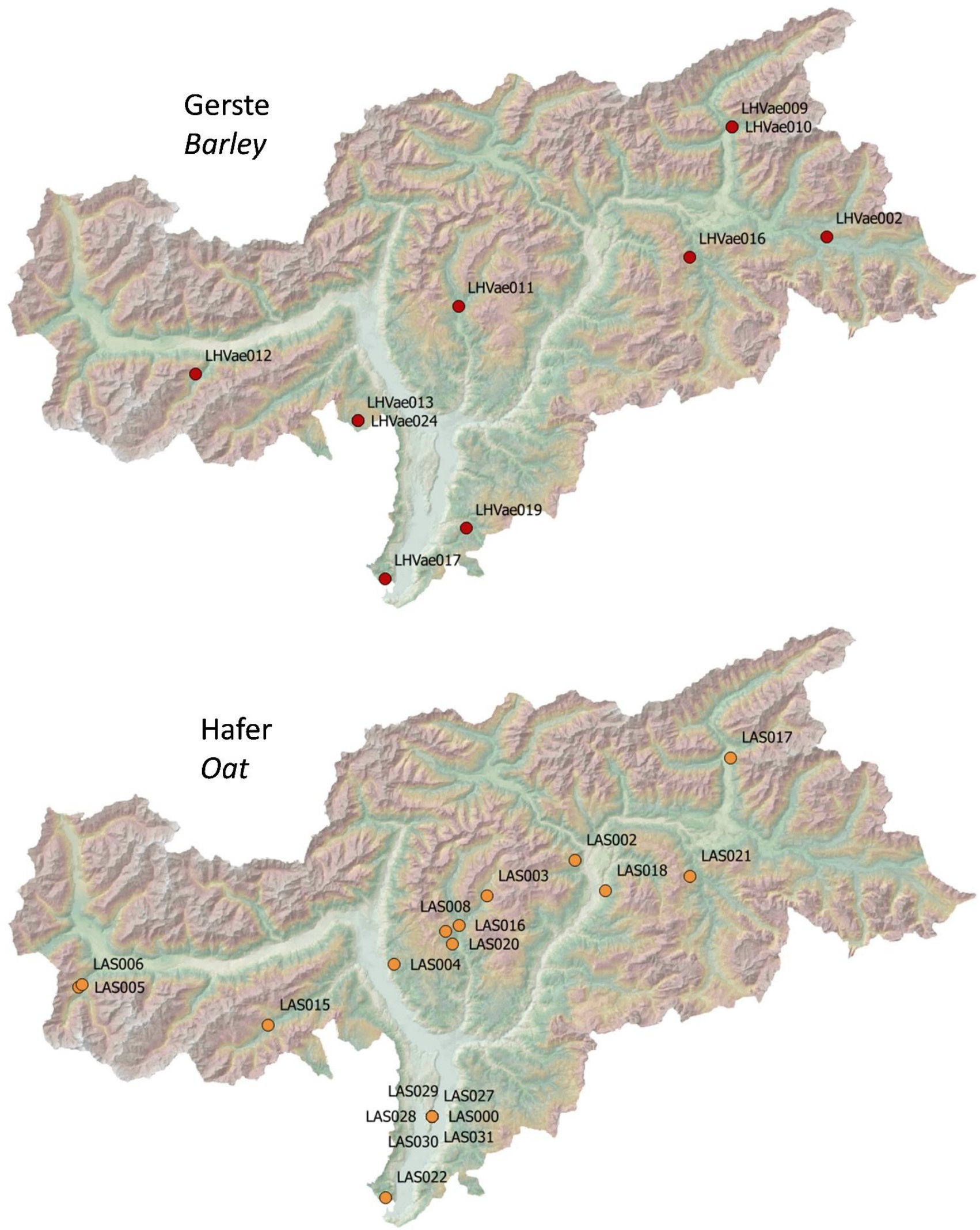

Abb. 14: Herkunft der beschriebenen Gerste- und Haferlandsorten. Haferlandsorten mit fehlender Angabe der Herkunft (LAS000, LAS027, LAS028, LAS029, LAS030, LAS031) werden auf der Karte beim Sitz der Genbank des Versuchszentrums Laimburg dargestellt. // Provenance of the described barley and oat landraces. Oat landraces without information about the sampling location (LASO00, LASO27, LASO28, LASO29, LASO30, LASO31) are shown in the map at the location of the Laimburg gene bank. 


\section{ANHANG 4: DESKRIPTORENLISTEN}

Tab. 5: Deskriptorenliste für Weizen // List of descriptors for wheat.

\begin{tabular}{|c|c|c|c|}
\hline $\begin{array}{c}\text { Merkmal } \\
\text { Trait }\end{array}$ & $\begin{array}{l}\text { Zeitpunkt der Be- } \\
\text { schreibung a } \\
\text { Assessment time a }\end{array}$ & $\begin{array}{l}\text { Typ b } \\
\text { Type }^{b}\end{array}$ & Range (ranks number) \\
\hline Saisonalität & & $\mathrm{QL}$ & Winter / Wechselform / Sommer (3) \\
\hline Habitus & & QL & einjährig / zweijährig / mehrjährig (3) \\
\hline Wuchsform & 13 bis 14 & $\mathrm{HQ}$ & aufrecht bis liegend (5) \\
\hline Blattstellung & 22 bis 29 & $\mathrm{HQ}$ & aufrecht bis flach (3) \\
\hline Blattbereifung & MS 4 & $\mathrm{HQ}$ & fehlend bis stark (4) \\
\hline Blatthäutchen & MS 4 & QL & fehlend / vorhanden (2) \\
\hline Fahnenblattstellung & 51 & $\mathrm{HQ}$ & aufrecht bis überhängend (5) \\
\hline Fahnenblattlänge $(\mathrm{cm})$ & 51 & QT & \\
\hline Fahnenblattbreite $(\mathrm{cm})$ & 51 & QT & \\
\hline Halmfarbe oberstes Internodium & MS 5 & QL & hellgrün / grün / violett (3) \\
\hline Datum (Tage ab Aussaat) & 55 & QT & \\
\hline Halmbereifung & MS 6 & $\mathrm{HQ}$ & fehlend bis sehr stark (5) \\
\hline Ährenbereifung & MS 6 & $\mathrm{HQ}$ & unbereift bis stark bereift (4) \\
\hline Halmstärke 2. Internodium (mm) & 73 bis 77 & QT & \\
\hline Halmfüllung (oberstes Internodium) & 73 bis 77 & $\mathrm{HQ}$ & fehlend bis voll (5) \\
\hline Halmlänge $(\mathrm{cm})$ & $a b 73$ & QT & \\
\hline Begrannung & 73 bis 77 & QL & unbegrannt bis lang begrannt (5) \\
\hline Grannenfarbe & 73 bis 77 & QL & wie Ähre / anders als Ähre (2) \\
\hline Ährenfarbe & 73 bis 77 & QL & $\begin{array}{l}\text { gelbgrün / hellgrün / grün / dunkelgrün / grau grün } \\
\text { / blau grün / hellviolett / violett / anders (9) }\end{array}$ \\
\hline Ährenhaltung & 87 & $\mathrm{HQ}$ & aufrecht bis nickend (3) \\
\hline Ausfallneigung & ab 89 & $\mathrm{HQ}$ & fehlend bis stark (4) \\
\hline Ährenlänge (cm) & ab 89 & QT & \\
\hline Ährendichte (Stufen / 5 cm) & $a b 89$ & QT & \\
\hline Ährenform & ab 89 & $\mathrm{QL}$ & $\begin{array}{c}\text { pyramidal / parallel / spindelförmig/keulenförmig / } \\
\text { anders (5) }\end{array}$ \\
\hline Körner pro Spindelglied (Anzahl) & ab 89 & QT & \\
\hline Hüllspelzenfarbe & ab 89 & QL & weiß (gelb) / rot bis braun / purpurn bis schwarz (3) \\
\hline Auswuchsneigung & 99 & $\mathrm{HQ}$ & fehlend bis stark (3) \\
\hline Kornform & 99 & $\mathrm{QL}$ & rund / fassförmig, oval / länglich/buckelig (4) \\
\hline Samenfarbe & 99 & QL & weiß / rot / braun / purpurn (4) \\
\hline Tausendkorngewicht (g) & 99 & QT & \\
\hline Samenfaltentiefe & 99 & QL & $\begin{array}{l}\text { flach eng / flach weit / mitteltief / sehr tief eng / } \\
\text { mitteltief weit (5) }\end{array}$ \\
\hline Hektolitergewicht $\left(\mathrm{kg} \mathrm{hl}^{-1}\right)$ & 99 & QT & \\
\hline Ertrag (dt ha $\left.{ }^{-1}\right)$ & 99 & QT & \\
\hline
\end{tabular}

a Entwicklungsstadium nach der entsprechenden BBCH-Skala, MS ist das Makrostadium //a Growth stage according to the respective BBCH-scale, MS is the principal growth stage.

${ }^{b} \mathrm{QL}=$ qualitativ, $\mathrm{HQ}=$ halbquantitativ, $\mathrm{QT}=$ quantitativ $/ /{ }^{\mathrm{b}} \mathrm{Q} L=$ qualitative, $H \mathrm{Q}=$ semi-quantitative, $\mathrm{Q} T$ = quantitative. 
Tab. 6: Deskriptorenliste für Roggen // List of descriptors for rye.

\begin{tabular}{|c|c|c|c|}
\hline $\begin{array}{c}\text { Merkmal } \\
\text { Trait }\end{array}$ & $\begin{array}{l}\text { Zeitpunkt der Be- } \\
\text { schreibung a } \\
\text { Assessment time a }\end{array}$ & $\begin{array}{l}\text { Typ }{ }^{b} \\
\text { Type }^{b}\end{array}$ & Range (ranks number) \\
\hline Saisonalität & & QL & Winter / Wechselform / Sommer (3) \\
\hline Wuchsform & 13 bis 14 & $\mathrm{HQ}$ & aufrecht bis breit liegend (4) \\
\hline Blattstellung & 22 bis 29 & $\mathrm{HQ}$ & aufrecht bis flach (3) \\
\hline Bestockungskapazität & 22 bis 29 & $\mathrm{HQ}$ & gering / hoch (2) \\
\hline Blattbereifung & MS 4 & $\mathrm{HQ}$ & fehlend bis stark (4) \\
\hline Fahnenblattstellung & 51 & $\mathrm{HQ}$ & aufrecht bis hängend (3) \\
\hline Datum (Tage ab Aussaat) & 55 & QT & \\
\hline Datum (Tage ab Aussaat) & 65 & QT & \\
\hline Fahnenblattlänge (cm) & MS 6 & QT & \\
\hline Fahnenblattbreite $(\mathrm{cm})$ & MS 6 & QT & \\
\hline Blattdrehung & MS 6 & $\mathrm{HQ}$ & fehlend bis stark (4) \\
\hline Halmbereifung & MS 6 & $\mathrm{HQ}$ & fehlend bis stark (4) \\
\hline Halmfarbe & MS 6 & QL & grün / gelb / grau / blau (4) \\
\hline Standfestigkeit & MS 6 & $\mathrm{HQ}$ & aufrecht bis liegend (4) \\
\hline Halmbehaarung unter der Ähre & MS 6 & $\mathrm{HQ}$ & fehlend bis stark (4) \\
\hline Ährenfarbe & 73 bis 77 & QL & grün / gelb / blau / grau (4) \\
\hline Ährenbereifung & 73 bis 77 & $\mathrm{HQ}$ & fehlend bis stark (4) \\
\hline Grannenlänge & 73 bis 77 & QL & unbegrannt / kurz / fein / grob, lang (4) \\
\hline Grannenfarbe & 73 bis 77 & QL & wie Ähre / anders als Ähre (2) \\
\hline Wuchshöhe (cm) & 73 bis 77 & QT & \\
\hline Schwarzrostbefall & 88 bis 92 & $\mathrm{HQ}$ & fehlend bis sehr stark (4) \\
\hline Wuchshöhe (cm) & 89 & QT & \\
\hline Ährenhaltung & 89 & $\mathrm{HQ}$ & aufrecht bis stark überhängend (5) \\
\hline Ährendichte (Stufen / 5 cm) & ab 89 & QT & \\
\hline Ährenform & ab 89 & QL & parallel / fischförmig / pyramidal (3) \\
\hline Ährenlänge (cm) & $a b 89$ & QT & \\
\hline Ährenbreite (mm) & ab 89 & QT & \\
\hline Körner pro Spindelglied (Anzahl) & ab 89 & QT & \\
\hline Standfestigkeit & 89 & $\mathrm{HQ}$ & aufrecht bis liegend (4) \\
\hline Ausfallneigung & 92 & $\mathrm{HQ}$ & sehr schwacher bis vollständigen Ausfall (4) \\
\hline Auswuchsneigung & 99 & $\mathrm{HQ}$ & fehlend bis stark (3) \\
\hline Samenfarbe & 99 & QL & weiß / grau / grün / braun / purpurn / anders (6) \\
\hline Kornform & 99 & QL & $\begin{array}{l}\text { oval / länglich-oval / fassförmig / beidseitig zusam- } \\
\text { mengedrückt / anders (5) }\end{array}$ \\
\hline Tausendkorngewicht (g) & 99 & QT & \\
\hline Hektolitergewicht $\left(\mathrm{kg} \mathrm{hl}^{-1}\right)$ & 99 & QT & \\
\hline Ertrag (dt ha-1) & 99 & QT & \\
\hline
\end{tabular}

a Entwicklungsstadium nach der entsprechenden BBCH-Skala, MS ist das Makrostadium // a Growth stage according to the respective BBCH-scale, MS is the principal growth stage.

${ }^{\mathrm{b}} \mathrm{QL}=$ qualitativ, $\mathrm{HQ}=$ halbquantitativ, $\mathrm{QT}=$ quantitativ $/ /{ }^{\mathrm{b}} \mathrm{QL}=$ qualitative, $\mathrm{HQ}=$ semi-quantitative, $\mathrm{QT}=$ quantitative. 
Tab. 7: Deskriptorenliste für Gerste. // List of descriptors for barley.

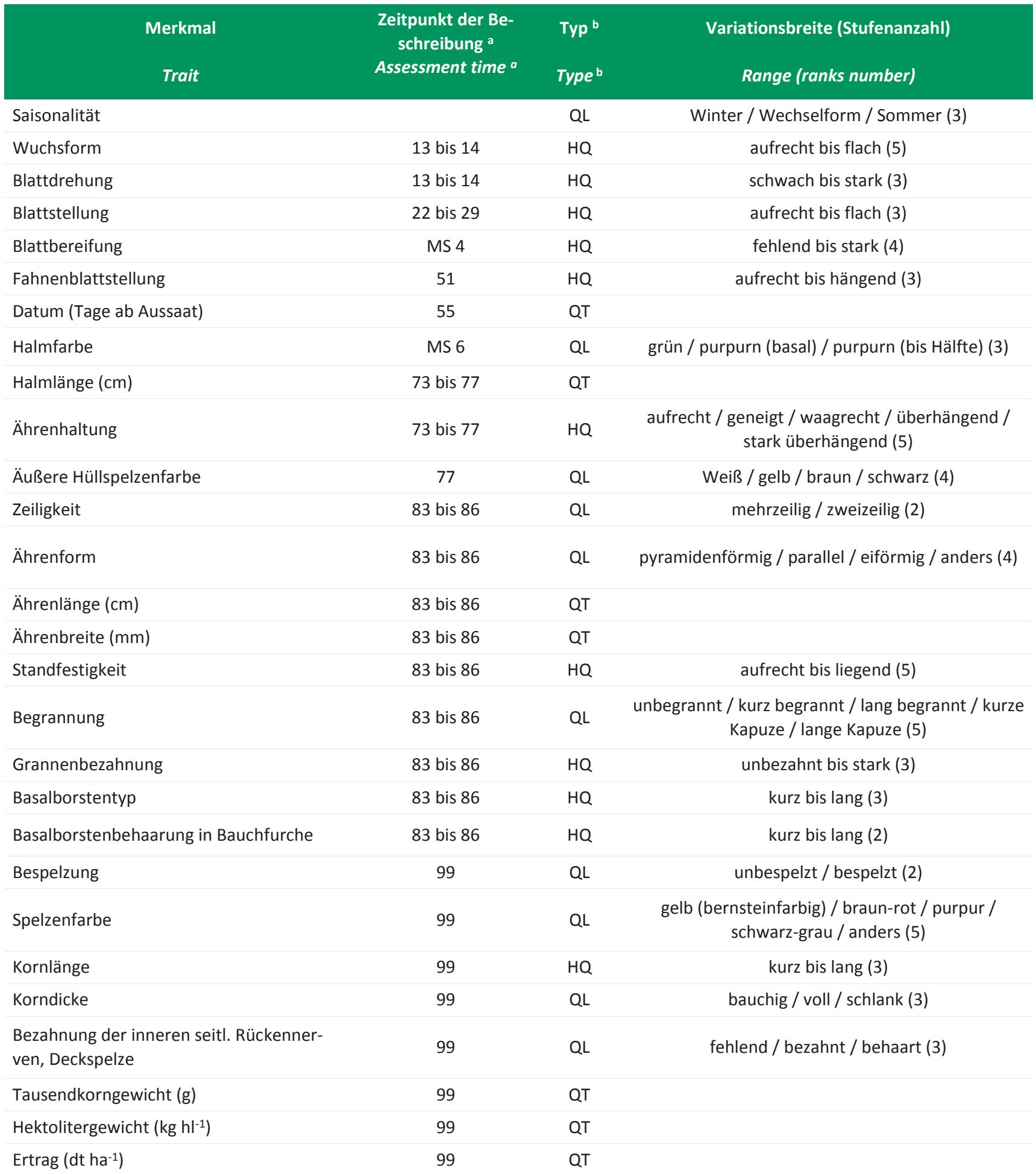

a Entwicklungsstadium nach der entsprechenden BBCH-Skala, MS ist das Makrostadium // a Growth stage according to the respective BBCH-scale, MS is the principal growth stage.

${ }^{\mathrm{b}} \mathrm{QL}=$ qualitativ, $\mathrm{HQ}=$ halbquantitativ, $\mathrm{QT}=$ quantitativ $/ /{ }^{\mathrm{b}} \mathrm{QL}=$ qualitative, $\mathrm{HQ}=$ semi-quantitative, $\mathrm{QT}$ = quantitative. 
Tab. 8: Deskriptorenliste für Hafer // List of descriptors for oat.

\begin{tabular}{|c|c|c|c|}
\hline $\begin{array}{l}\text { Merkmal } \\
\text { Trait }\end{array}$ & $\begin{array}{l}\text { Zeitpunkt der Be- } \\
\text { schreibung a } \\
\text { Assessment time }{ }^{a}\end{array}$ & $\begin{array}{l}\text { Typ }{ }^{b} \\
\text { Type }^{b}\end{array}$ & $\begin{array}{l}\text { Variationsbreite (Stufenanzahl) } \\
\text { Range (ranks number) }\end{array}$ \\
\hline Saisonalität & & QL & Winter / Wechselform / Sommer (3) \\
\hline Aufwuchshabitus & 13 bis 14 & $\mathrm{HQ}$ & aufrecht bis flach (5) \\
\hline Blattdrehung & 13 bis 14 & QL & links / recht (2) \\
\hline Spitzenblattstellung & 51 & $\mathrm{HQ}$ & aufrecht bis hängend (3) \\
\hline Blattstellung außer Spitzenblatt & 51 & $\mathrm{HQ}$ & aufrecht bis hängend (3) \\
\hline Spitzenblattsteifigkeit & 51 & $\mathrm{HQ}$ & weich bis starr, steif (3) \\
\hline Blattsteifigkeit außer Spitzenblatt & 51 & $\mathrm{HQ}$ & weich bis starr, steif (3) \\
\hline Blattscheidenbehaarung & 51 & $\mathrm{HQ}$ & unbehaart bis stark behaart (4) \\
\hline Blattrandbehaarung & 51 & $\mathrm{HQ}$ & unbehaart bis stark behaart (4) \\
\hline Blattbereifung & 51 & QL & fehlend / vorhanden (2) \\
\hline Datum (Tage ab Aussaat) & 55 & QT & \\
\hline Blattlänge des vorletzten Blattes $(\mathrm{cm})$ & 55 & QT & \\
\hline Blattbreite des vorletzten Blattes $(\mathrm{cm})$ & 55 & QT & \\
\hline Rispenform & 73 bis 77 & QL & $\begin{array}{c}\text { Fahnenrispe / Steifrispe eng / Steifrispe weit / } \\
\text { Steifrispe oben eng unten weit / Sperrrispe / } \\
\text { Sperrrispe weit /Schlaffrispe /Starrispe / Nack- } \\
\text { thaferrispe (9) }\end{array}$ \\
\hline Wuchshöhe (cm) & 73 bis 77 & QT & \\
\hline Halmknotenbehaarung & 73 bis 77 & $\mathrm{HQ}$ & unbehaart bis stark behaart (4) \\
\hline Lagerung & 73 bis 77 & $\mathrm{HQ}$ & fehlend bis total (5) \\
\hline Rispenstellungswinkel & 73 bis 85 & $\mathrm{HQ}$ & extrem aufrecht bis hängend (4) \\
\hline Ährchenhaltung & 73 bis 85 & $\mathrm{HQ}$ & hängend bis aufrecht (3) \\
\hline Rispenbereifung & 73 bis 85 & QL & fehlend/vorhanden (2) \\
\hline Datum (Tage ab Aussaat) & 87 & QT & \\
\hline Lagerung & 89 & $\mathrm{HQ}$ & fehlend bis total (5) \\
\hline Reifeunterschied Korn / Stroh & 89 & QL & $\begin{array}{l}\text { Korn vor dem Stroh reif / Korn zugleich mit dem } \\
\text { Korn reif / Stroh vor dem Korn reif (3) }\end{array}$ \\
\hline Körner pro Ährchen (Anzahl) & 89 & QT & \\
\hline Rostbefall & 92 & $\mathrm{HQ}$ & fehlend bis sehr stark (4) \\
\hline Spelzenfarbe & 99 & QL & weiß / gelb / grau / rot / braun / schwarz (6) \\
\hline Spelzenbehaarung & 99 & $\mathrm{HQ}$ & unbehaart bis stark behaart (4) \\
\hline Kornbasisbehaarung & 99 & $\mathrm{HQ}$ & unbehaart bis stark behaart (4) \\
\hline Hüllspelzen & 99 & QL & Fehlend / vorhanden (2) \\
\hline Begrannung & 99 & $\mathrm{HQ}$ & unbegrannt bis stark begrannt (3) \\
\hline Grannentyp & 99 & QL & gerade / gebogen / gedreht / geknickt/ \\
\hline Grannenposition & 99 & $\mathrm{HQ}$ & $\begin{array}{l}1 / 4 \text { von der Basis } / 1 / 3 \text { von der Basis } / 1 / 2 \text { von der Ba- } \\
\qquad \text { sis / > }>1 / 2 \text { von der Basis (4) }\end{array}$ \\
\hline Tausendkorngewicht (g) & 99 & QT & \\
\hline Auswuchsneigung & 99 & $\mathrm{HQ}$ & fehlend bis stark ( 3 ) \\
\hline Ertrag (dt ha-1) & 99 & QT & \\
\hline
\end{tabular}

a Entwicklungsstadium nach der entsprechenden BBCH-Skala // a Growth stage according to the respective BBCH-scale

${ }^{b} \mathrm{QL}=$ qualitativ, $\mathrm{HQ}=$ halbquantitativ, $\mathrm{QT}=$ quantitativ $/ /{ }^{\mathrm{b}} \mathrm{QL}=$ qualitative, $H Q=$ semi-quantitative, $Q T$ = quantitative. 
